\title{
Prognostic utility of the assessment of diastolic function in patients undergoing cardiac
} resynchronization therapy

Galli $\mathrm{E}^{1}$, MD, PhD; Smiseth $\mathrm{OA}^{2}$, MD, PhD; Aalen $\mathrm{JM}^{2}$, MD, PhD; Larsen $\mathrm{CK}^{2}$, MD; Sade $\mathrm{E}^{3}$, MD, PhD; Hubert A ${ }^{1}, \mathrm{MD}$; Anilkumar $\mathrm{S}^{4}, \mathrm{MD}$; Penicka $\mathrm{M}^{6}, \mathrm{MD}, \mathrm{PhD}$; Cecilia Linde ${ }^{7}, \mathrm{MD}, \mathrm{PhD}$;

Le Rolle $\mathrm{V}^{1}$, PhD; Hernandez A ${ }^{1}$, PhD; Leclercq $C^{1}$, MD, PhD; Duchenne J ${ }^{8}$, PhD; Voigt J-U ${ }^{8}$, MD, PhD; Donal E ${ }^{1}, \mathrm{MD}, \mathrm{PhD}$.

${ }^{1}$ Univ Rennes, CHU Rennes, Inserm, LTSI - UMR 1099, F-35000 Rennes, France

${ }^{2}$ Institute for Surgical Research and Department of Cardiology, Osln ¿'niversity Hospital and

University of Oslo, Norway

${ }^{3}$ Department of Cardiology, Baskent University Hospital. A $\mathbf{L}_{\mathrm{L}}{ }^{\prime}$ ara, Turkey

${ }^{4}$ Non-Invasive Cardiac Laboratory, Department of Cardı'ngy, Heart Hospital, Hamad Medical Corporation, Doha, Qatar

${ }^{5}$ Ostlandske Hjertesenter, Moss, Norway

${ }^{6}$ Cardiovascular Center Aalst, OLV Clinic, Aalst, Belgium

${ }^{7}$ Heart and Vascular Theme, Karolins ${ }^{1}$ a $\left({ }^{\top} r_{\text {}}\right.$ versity Hospital and Karolinska Institutet, Stockholm, Sweden

${ }^{8}$ Department of Cardiovascular Pir ease and Departement of Cardiovascular Science, KU Leuven, Belgium

\section{Corresponding Author:}

Pr Erwan Donal

CHU Pontchaillou

2 Rue Henri Le Guilloux, 35000 Rennes - FRANCE

Tel.: +33299287896

Fax: +33299282529

E-mail: erwan.donal@chu-rennes.fr 
Declaration of interest: nothing to disclose 


\begin{abstract}
Conflicting data exist about the relationship between cardiac resynchronization therapy (CRT) and diastolic function.

Aims of the study are to assess diastolic patterns in patients undergoing CRT according to the 2016 recommendations of the American Society of Echocardiography/European Association of Cardiovascular Imaging and to evaluate the prognostic value of diastolic dysfunction (DD) in CRT candidates.
\end{abstract}

\title{
Methods and results
}

One-hundred ninety-three patients (age: $67 \pm 11$ years, QRS w dth: $167 \pm 21 \mathrm{~ms}$ ) were included in this multicentre prospective study. Mitral filling pattern, mitr al issue Doppler velocity, tricuspid regurgitation velocity, and indexed left atrial volume wıre used to classify DD from grade I to III. CRT-response, defined as a reduction of left ven. icular (LV) end-systolic volume $>15 \%$ at 6month follow-up (FU), occurred in 132 (68\%, natients. The primary endpoint was a composite of heart transplantation, LV assisted device : $\mathrm{m}_{\mathrm{r}}$ ' 'ntation, or all-cause death during FU and occurred in $29(15 \%)$ patients.

CRT was associated with a degreda: ${ }^{2}$ of DD in non-responders. At multivariable analysis corrected for clinical variab $^{1} \mathrm{~s}, 2 \kappa S$ duration, mitral regurgitation, CRT-response and LV dyssynchrony, grade I DD w s associated with a better outcome (HR 0.37, 95\% CI: 0.14-0.96). Non-responders with grade II-III DD had the worse prognosis (HR 4.36, 95\%CI: 2.10-9.06).

\section{Conclusions}

The evaluation of DD in CRT candidates allows the prognostic stratification of patients, independently from CRT-response. 
Word count: 4.868 


\section{Introduction}

Cardiac resynchronization therapy (CRT) has a pivotal role in the management of patients with systolic heart failure (HF) and QRS width> $120 \mathrm{~ms}(1)$. Successful CRT has been demonstrated to attenuate HF symptoms, reduce HF-related hospitalization, and to induce left ventricular (LV) remodelling, by a reduction in LV-end systolic volume (LV-ESV) and increase in LV ejection fraction $(\mathrm{LVEF})(2)$.

Recent studies have shown that diastolic dysfunction (DD) is associated with increased mortality in patients with HF and reduced ejection fraction (3),(4). The best moda. ${ }^{\text {ty }}$ to assess diastolic function in CRT-candidates is an object of debate and the relations' 14 between diastolic function, CRTresponse and survival is not definitely understood(5).

The application of the multiparametric approach proped by Nagueh et al. in the 2016 Recommendations of the American Society oi F chocardiography/European Association of Cardiovascular Imaging(6) is discouraged i. vr ient with left bundle branch block (LBBB) or paced rhythm because of the lack of inva ive validation. Despite the intrinsic limitations of recommendations, a recent prospective $n$ sticenter study conducted on 450 patients with several different heart disease, demonsti tes that the algorithm proposed by Nagueh et al. was able to identify patients with elevated $L^{V}+$ illing pressure against the invasive gold standard also in the case of LBBB or paced rhythn' 'aıd under the curve=0.84)(7). These results justify testing the value of recent recommendations on diastolic function in CRT candidates.

The aims of the present study are: 1) to describe the impact of CRT on diastolic function assessed using current recommendations; 2) to evaluate the prognostic impact of diastolic dysfunction in CRT candidates.

\section{Methods}

\section{Population}

209 patients with systolic HF undergoing CRT implantation according to current guidelines(1) at Oslo University Hospital (Norway), Leuven University Hospital (Belgium), 
Rennes University Hospital (France), and Aalst OLV Hospital (Belgium), and Karolinska University Hospital, Sweden between August 2015 and November 2017 were prospectively included in this observational, multicentre study.

Sixteen patients were excluded from the final analysis because of study withdrawal $(n=4)$, lead extraction due to infective endocarditis $(\mathrm{n}=1)$, and lack of fundamental echocardiographic data $(n=11)$. At the time of CRT implantation, all patients were receiving optimized medical therapy. Clinical data including age, sex, and treatments were collected for each patient. The functional status was assessed by the estimation of the New York Heart Assnriainn (NYHA) functional class. Ischemic heart disease was defined as a history of myocardial ini? rction and coronary revascularization or angiographic evidence of multiple vecse tisease or single-vessel disease with $\geq 75 \%$ stenosis of the left main or proximal left anterior res ${ }^{\prime}$ nding artery(8). All patients gave their written informed consent for study participation.

The study was conducted following the "Gc nd clinical Practice" guidelines of the Declaration of Helsinki and was approved by the Regiona ${ }^{1}$ Ethical Committees of every participating centre. The study was registered at clinicaltrials. gnv (ir entifier NCT02525185).

\section{Echocardiography}

All patients underwent sı'n`ard transthoracic echocardiography using a Vivid E9 or E95 ultrasound system (GE He. 'trı are, Horten, Norway) equipped with an M5S 3.5-MHz transducer at baseline and 6-month follow-up. Two-dimensional, colour Doppler, pulsed-wave and continuouswave Doppler data were stored on a dedicated workstation for the offline analysis (EchoPAC, GE EchoPAC, GE Healthcare, Horten, Norway). Left atrial, LV volumes, and LVEF were measured by the biplane method, as recommended(9). Indexed LV mass (LVMi) and relative wall thickness (RWT) were assessed as recommended(9).

Mitral regurgitation (MR) was visually assessed from 1 to 3 (1=traces to mild MR; $2=$ moderate MR; 3=moderate-to-severe MR). Peak velocity of early (E) and late (A) diastolic filling were derived from transmitral Doppler recordings, and the E/A ratio was calculated. Pulsed-wave TDI- 
derived early diastolic velocity were obtained at the septal and lateral mitral annulus and the mean value (e') was used to estimate the E/e' ratio. In the presence of tricuspid regurgitation, continuous Doppler was used to estimate maximal tricuspid velocity $\left(T R V_{\max }\right)$. Inferior vena cava diameter and respiratory changes, and $\mathrm{TRV}_{\max }$ were then used to estimating systolic pulmonary artery pressure (PAPs)(10). To assess diastolic function, the algorithm proposed by Nagueh et al. was applied(6). The combination of mitral filling pattern, indexed LA volume $\left(\mathrm{LAV}_{\mathrm{i}}\right), \mathrm{E} / \mathrm{e}^{\prime}$ ratio, and $\mathrm{TRV}_{\max } \mathrm{was}$ used at both baseline and 6-month FU to classify DD from grade I to grade III. In the case of "grey zone" values for these variables, diastolic function was indicated ac " 1 - determinate"(6) (Figure 1).

\section{Assessment of LV dyssynchrony}

Septal flash (SF) and apical rocking (ApR) were as assed visually by two experienced readers from the KU Leuven. In case of disagreer Ie. third reading was performed in Leuven by an independent expert to reach a consensus. SF defined as pre-ejection septal shortening or rapid leftward septal motion immediately after v'set QRS and was assessed visually in apical 2D images or, when in doubt, with longitudinal strai ',r M-mode in parasternal views(11). ApR was defined as a transverse rightward motion of $\mathfrak{i}$ e apex immediately after onset QRS, followed by a leftward motion of the apex during ejectı n( 12). LV mechanical dyssynchrony was defined by the presence of SF and/or ApR.

\section{Cardiac resynchronization therapy}

CRT delivery followed a standardized protocol. The right atrial and ventricular leads were positioned conventionally. The LV lead was inserted in a lateral or postero-lateral vein if possible and coronary venography was used to optimize lead placement. The device was programmed in a conventional biventricular pacing and CRT was optimized before discharge if needed.

Positive response to CRT was defined as a decrease in LV end-systolic volume of $\geq 15 \%$ (13). To optimize precision for the assessment of CRT response, all volumes were measured independently 
in three different centres (Rennes, Leuven and Oslo). The percent variation in LV-ESV was calculated to evaluate CRT-response and a majority decision was used in cases of disagreement between 2 centers. We also assessed reproducibility for LV-ESVs measured in every centre. The interclass correlation coefficients (ICC) were 0.97 (0.96-0.98, p<0.0001), 0.89 (0.74-0.94, $\mathrm{p}<0.0001), 0.95(0.87-0.98, \mathrm{p}<0.0001)$ for the LV-ESVs assessed in Rennes and Oslo, in Rennes and Leuven, and in Oslo et Leuven, respectively. The correlations between the volumes assessed in the centres and the corresponding Bland-Altman plot are displayed in Supplementary Figure 1.

\section{Study endpoints}

The primary endpoint was a composite of heart In 'splantation, LV assisted device implantation, or all- cause death during follow-up.

\section{Statistical analysis}

Continuous variables are expressed $\&$, the mean and standard deviation and were compared using Student's t-test. Categorical data are ×xpressed as frequencies and percentages and were compared by the $\chi^{2}$ test. Inter-observer vi ri bility for the estimation LV-ESV between the three enrolling centres was assessed by : neaı regression analysis, and Bland-Altman plots and is displayed in Supplementary Fig re 1. Interclass correlation coefficients (ICC) were also reported. The relation between varia: 'les was assessed by bivariate analysis with Pearson's correlation coefficients. Cox-regression analysis and Kaplan-Meier curves with log-rank test were used to describe survival data. All statistical analyses were performed using a standard statistical software program (SPSS Version 20.0, IBM, Chicago, IL, USA).

\section{Results}

One-hundred ninety-three patients (age $67 \pm 11$ years, males $70 \%$ ) met the eligibility criteria within the study period. Clinical and echocardiographic data from the overall population and according to CRT-response are provided in Table 1 and 2. Ischemic heart disease was diagnosed in 
$64(33 \%)$ patients. Atrial fibrillation was detected in $11(5.6 \%)$ patients. Typical left bundle branch block (LBBB) according to Strauss(14) was observed in 168 (87\%) patients. LV mechanical dyssynchrony was observed in 136 (70\%) patients. At 6-month FU, volumetric response to CRT was observed in $132(68 \%)$ patients. Responders were more often women, with a lower prevalence of ischemic cardiomyopathy. LV dyssynchrony was observed in 136 (70\%) patients and was prevalent in responders ( $82 \%$ vs $44 \%, \mathrm{p}<0.0001)$. LVMi and RWT were similar in responders and were in favour of an eccentric LV hypertrophy. CRT-induced a significant reduction in MR entity in both responders $(1.5 \pm 0.9$ vs $1.0 \pm 0.05, \mathrm{p}<0.01)$ and non-responders $(1.6 \pm 1.0$ vs $1.2 \pm 0.6, \mathrm{p}<0.01)$. Responders had less significant LV dilatation at baseline. At ı i'vw-up, LVEF, and GLS improved substantially in responders, while in non-responders there vare no significant changes. (Table 2).

\section{Assessment of diastolic dysfunction}

Before CRT implantation, the parameter $c^{\prime} d^{\prime}$ astolic function including $E$ wave velocity, E/e', $\mathrm{LAV}_{\mathrm{i}}$, and $\mathrm{TRV}_{\max }$ were significantly Ilt $_{i}$ ied in non-responders. CRT delivery was associated with a significant reduction in $\mathrm{LAV}_{\mathrm{i}}$ and $\mathrm{L}^{\prime \prime} \mathrm{e}^{\prime}$ in responders, whereas only a mild reduction in LAVi was observed in non-responders (Tahle 2;

Before CRT, the prevalence of gr $\mathrm{le}$ l, grade II, grade III DD in the overall were respectively 55\%, 24\%, and 13\% (Figure 2A). Pat $\mathbf{n}^{+} j$ with grade I DD were younger, had less ischemic cardiomyopathy and less 1. naired renal function. They needed less diuretics and aldosteroneantagonists. Despite the absence of significant difference in LV size and LVEF at baseline, grade I DD was associated with a marked reverse remodelling at FU (Table 3).

The prevalence of grade I DD before CRT delivery was significantly higher in responders (Figure 2B). After CRT, the prevalence of grade III DD increased in non-responders ( $20 \%$ vs $25 \%$, p=0.05) (Figure 2C). In responders, CRT was associated with a slightly decreased prevalence of grade I DD, and increased prevalence of "indeterminate" diastolic dysfunction (Figure 2D).

\section{Predictors of prognosis.}


After a mean follow-up period of 35 months, 27 patients died, 1 patient received LVAD, and 1 patient was transplanted. Three patients reached the primary endpoint before 6-month follow-up and these patients were considered non-responders.

The algorithm by Nagueh et al. was able to predict prognosis in CRT-candidates. As displayed in Table 4, when using Grade I DD as reference, patients assigned to grade II (HR 6.04, 95\% CI: 2.3215.77) and III DD (HR 4.64, 95\%CI: 1.49-14.39) had a significant increased risk of events. However, no significant difference was observed between grade II and III DD for the prediction of events (HR 0.77, 95\% CI 0.29-2.00. Therefore, Grade II and sraa III DD were merged in the multivariable analysis (Table 4, Panel B). Other predictors cr. p. gnosis at univariable analysis are displayed in Table 4, Panel A. At multivariable analysis corı-ted for clinical variables, QRS width, mitral regurgitation, CRT-response and LV dyssynchro'yy, srade I DD was associated with a better outcome (HR 0.37, 95\% CI: 0.14-0.96) (Fiģ e 3). Two multivariable models including

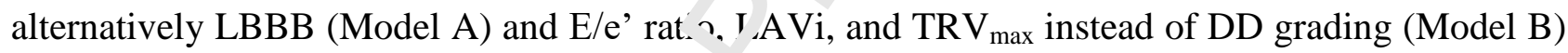
are provided as Supplementary Material. in the multivariable including LBBB, this parameter was not a predictor of prognosis (Figıre 5?). Similarly, diastolic function parameters lose their predictive value at multivariable a. alysis (Table 3, Figure S3).

Kaplan-Meier survival curves s.o ved that grade I DD was associated with a significantly better outcome $\left(\log\right.$-rank $\mathrm{p}<0.0 \mathrm{u}^{1}{ }^{1}$ ) (rigure $\left.4 \mathrm{~A}\right)$ and with a significantly reduced risk of events (HR 0.18 , 95\% CI: 0.07-0.45, $\mathrm{p}<0.0001)$.

Grade I DD was associated with a better prognosis among both CRT responders and nonresponder. Non-responders with grade II-III DD had the worse outcome (HR 4.36, 95\%CI: 2.10 9.06, $\mathrm{p}<0.0001)($ Figure 4B)

Similarly, the assessment of DD allowed the prognostic stratification of patients with and without LV dyssynchrony (log-rank $\mathrm{p}<0.0001)$. Patients without SF/ApR and with grade II-III DD had the worse prognosis (HR 4.41, 95\%CI: 2.11-9.17, p<0.0001) (Figure 4C).

\section{Discussion}


The present multicentre prospective study applies current recommendations for the assessment of diastolic dysfunction in CRT-candidates and shows that the presence of a relatively preserved diastolic function before CRT implantation is associated with a better prognosis.

\section{Diastolic dysfunction and CRT response}

The effect of CRT on diastolic function are still debated. Some prospective studies showed that a favourable filling pattern(15) and a less dilated left atrium (LA)(16) at baseline are more likely to be associated with a positive LV remodelling after CRT. In contrast, Yu et al. showed that the LV reverse remodelling induced by CRT is not influenced $h_{\mathrm{V}}$ he diastolic filling pattern at baseline(17).

In our study, the effect of CRT on DD was assessed by the ap nlication the 2016 Recommendations of the American Society of Echocardiography and the Exru ${ }_{1}$ ean Association of Cardiovascular Imaging. By the use of this comprehensive appro $c_{1}$. w'lich is based on the simultaneous estimations of several parameters, we obser ed chat CRT was associated with an increased prevalence of grade III DD in non-responci rs. The degradation of DD in non-responders is probably attributable to the absence of $\mathrm{L}^{\top}$, everse remodelling, which has a substantial influence on LV filling pressures.

In our population, CRT did nu crange the prevalence of grade I to III DD in responders. This observation is in partially in cuntrast with previous studies on this topic(15),(18),(19) and might be attributable to several different factors. First, the diagnostic algorithm for the classification of DD relies on specific cut-off values, which means that the simple modification of one or more parameters might not be enough to fulfil the criteria necessary for a change in diastolic function class. We observed a significant improvement in E/e' ratio and LAVi in responders, nevertheless, E/E' and LAVi remained above the predefined cut-off in $41 \%$ and $27 \%$ of patients at 6 -month FU. Second, in responders we observed an increased number of "indeterminate" DD at follow-up. This is mainly attributable to discordant DD parameters in patients with undetectable tricuspid 
regurgitation after $\mathrm{CRT}$. $\mathrm{TRV}_{\max }$ is a parameters that reflects advanced DD due to chronic pressure overload(20).

Almeida et al. have already observed that the addition of $\mathrm{TRV}_{\max }$ to the algorithm of Nagueh et al. was associated with an increased sensitivity and a drop of specificity for the detection of DD, particularly in patients with less advanced $\mathrm{DD}(21)$. This means that in responders with a significant improvement of LV function and decrease in LV filling pressure, the absence of data on $\mathrm{TRV}_{\max }$ at FU, might contribute to with a certain degree of patients' misclassification as “indeterminate DD”.

\section{Diastolic dysfunction and prognosis}

In this study we were able to demonstrate that patients with grade I DD undergoing CRT have a significantly better prognosis with respect to patients , ith more advanced DD at baseline. The prognostic value of the algorithm of Nagueh et al. for we assessment of DD has already been demonstrated in patients with $\mathrm{HF}$ and reduced $\mathrm{EF}\left(\mathbf{1}^{\mathrm{r}} \mathrm{Ar} \mathrm{r} \mathrm{F}\right)(3)$.

Our work expands this evidence by showin th $^{\text {th }}$ prognostic value of the 2016 recommendations in patients with HFrEF undergoing CRT. In c 'rr population, grade I DD was an independent predictor of prognosis. Patients with grade I DN at h.seline were younger, with lower prevalence of ischemic cardiomyopathy, and kidney failu'? Their clinical status was better before CRT-delivery, as evidenced by the lower NYHA $\iota^{1}{ }^{\prime} r_{s}$, better kidney function and the lower percentage of patients taking diuretics and aldosı "onc-antagonists. On the other hand, grade II and III DD at baseline were observed in patients with higher prevalence of ischemic cardiomyopathy, more advanced heart disease, and cardio-renal syndrome. These characteristics have already been associated with increased mortality in patients with a broad spectrum of cardiovascular disease and LV function (22) and might explain why grade II-III DD is associated with a poor survival in both CRT responders and non-responders. The prognostic value of SF/ApR in patients undergoing CRT has already been demonstrated(23). Nevertheless, Stankovic et al. have underscored that some patients with LV mechanical discoordination can have a poor prognosis because factors such as ischemic cardiomyopathy and advanced HF might contribute to their detrimental survival. In our population, 
we show that patients with grade I DD have probably less advanced HF, which can contribute its prognostic value in patients undergoing CRT, irrespectively to the presence of LV mechanical dyssynchrony.

\section{Clinical implications}

This study shows that the estimation of diastolic dysfunction by the algorithm proposed by Nagueh et al. is simple and applicable in a prospective cohort of "real life" patients undergoing CRT. Patients with grade I DD at baseline have less advanced HF, which has a fundamental prognostic impact and provide complementary information with recnes to LV mechanical dyssynchrony and CRT response which should prompt the as es nent of DD in CRT candidates.

\section{Limitations}

The main limitation of this study is the lack ₹f invasive validation for the assessment of LV filling pressure so that the classification of $\mathrm{DN} \mathrm{d}$, function is based only on the algorithm proposed in current recommendations. Although cardin - catheterization remains the gold standard for the

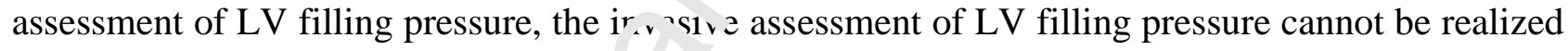
systematically in all patients. The rop sed algorithm for the assessment of DD has shown good accuracy in identifying the presı nce of elevated LV filling pressure in patients with very different cardiac disease, including $\mathrm{JBL}_{\mathrm{BL}} \mathrm{B}$ and paced rhythm(7). We therefore estimate that our results are reliable and have the merit to be largely applicable in everyday clinical practice. Another weakness of the algorithm is the impossibility to categorize some patients, because of discordances in the predefined diastolic function parameters. This intrinsic limitation of the current algorithm might be overcome in the future by the integration of new parameters, such as the assessment of left atrial deformation. Left atrial reservoir function correlates with LV filling pressure(24), has shown to be associated with prognosis in HF patients(25), and might therefore represent a potential new tool for the evaluation of diastolic dysfunction in CRT candidates(26). .

\section{Conclusions}


In CRT candidates, grade I DD is associated with a better prognosis. The evaluation of diastolic function according to the algorithm proposed by recommendations provide valuable prognostic information, which is additive to that provided by LV dyssynchrony or CRT response. 


\section{Funding:}

The study was supported by Center for Cardiological Innovation. JM Aalen was supported by a grant from the Norwegian Health Association. CK Larsen was recipient of a clinical research fellowship from the South-Eastern Norway Regional Health Authority. The study and J Duchenne were supported by a research grant of the University Leuven (OT12/084). JU Voigt holds a research mandate of the Research Foundation Flanders (FKM1832917N). 


\section{References}

1. Authors/Task Force Members, Brignole M., Auricchio A., et al. 2013 ESC Guidelines on cardiac pacing and cardiac resynchronization therapy: The Task Force on cardiac pacing and resynchronization therapy of the European Society of Cardiology (ESC). Developed in collaboration with the European Heart Rhythm Association (EHRA). Europace 2013;15(8):1070-118. Doi: 10.1093/europace/eut206.

2. Shamoun F., De Marco T., DeMets D., et al. Impact of Degree of Left Ventricular Remodeling on Clinical Outcomes From Cardiac Resynchronization Theranı Ji CC Heart Fail 2019;7(4):281-90. Doi: 10.1016/j.jchf.2018.11.004.

3. Hansen S., Brainin P., Sengeløv M., et al. Prognostic util ${ }_{1 \downarrow}^{\text {, }}$ of diastolic dysfunction and speckle tracking echocardiography in heart failure with reduc`d _ection fraction. ESC Heart Fail 2020;7(1):147-57. Doi: 10.1002/ehf2.12532.

4. Lüers C., Edelmann F., Wachter R., et al. Pr'gnostic impact of diastolic dysfunction in systolic heart failure-A cross-project analysis tr $\eta$ the German Competence Network Heart Failure. Clin Cardiol 2017;40(9):667-73. Doi: 1 n. 1 in $2 /$ clc. 22710.

5. Egnaczyk GF., Chung ES. The ?elaionship Between Cardiac Resynchronization Therapy and Diastolic Function. Curr Hea` F Fil Rep 2014;11(1):64-9. Doi: 10.1007/s11897-013-0181-5.

6. Nagueh SF., Smiseth G. , rppleton CP., et al. Recommendations for the Evaluation of Left Ventricular Diastolic Function by Echocardiography: An Update from the American Society of Echocardiography and the European Association of Cardiovascular Imaging. Eur Heart J Cardiovasc Imaging 2016;17(12):1321-60. Doi: 10.1093/ehjci/jew082.

7. Andersen OS., Smiseth OA., Dokainish H., et al. Estimating Left Ventricular Filling Pressure by Echocardiography. J Am Coll Cardiol 2017;69(15):1937-48. Doi: 10.1016/j.jacc.2017.01.058.

8. Felker GM., Shaw LK., O’Connor CM. A standardized definition of ischemic cardiomyopathy for use in clinical research. J Am Coll Cardiol 2002;39(2):210-8. 
9. Lang RM., Badano LP., Mor-Avi V., et al. Recommendations for cardiac chamber quantification by echocardiography in adults: an update from the American Society of Echocardiography and the European Association of Cardiovascular Imaging. J Am Soc Echocardiogr Off Publ Am Soc Echocardiogr 2015;28(1):1-39.e14. Doi: 10.1016/j.echo.2014.10.003.

10. Rudski LG., Lai WW., Afilalo J., et al. Guidelines for the echocardiographic assessment of the right heart in adults: a report from the American Society of Echocardiography endorsed by the European Association of Echocardiography, a registered branch of the European Society of Cardiology, and the Canadian Society of Echocardiography. J A m I x Echocardiogr Off Publ Am Soc Echocardiogr 2010;23(7):685-713; quiz 786-8. D л. ' U.1016/j.echo.2010.05.010.

11. Parsai C., Bijnens B., Sutherland GR., et al. Toward understanding response to cardiac resynchronization therapy: left ventricular dyssynchrs ny 's only one of multiple mechanisms. Eur Heart J 2009;30(8):940-9. Doi: 10.1093/el rı. ar.j/ehn481.

12. Voigt J-U., Schneider T-M., Korder $\$ .,-t$ al. Apical transverse motion as surrogate parameter to determine regional left veı 'ricular function inhomogeneities: a new, integrative approach to left ventricular asynchron_*ssessment. Eur Heart J 2009;30(8):959-68. Doi: 10.1093/eurheartj/ehp062.

13. Chung ES., Leon AR.. 1. vø zzi L., et al. Results of the Predictors of Response to CRT (PROSPECT) Trial. C1ı 'llauon 2008;117(20):2608-16. Doi:

\subsection{1/CIRCULATIONAHA.107.743120.}

14. Strauss DG., Selvester RH., Wagner GS. Defining left bundle branch block in the era of cardiac resynchronization therapy. Am J Cardiol 2011;107(6):927-34. Doi: 10.1016/j.amjcard.2010.11.010.

15. Gradaus R., Stuckenborg V., Loher A., et al. Diastolic filling pattern and left ventricular diameter predict response and prognosis after cardiac resynchronisation therapy. Heart 2008;94(8):1026-31. Doi: 10.1136/hrt.2007.126193. 
16. Hsu JC., Solomon SD., Bourgoun M., et al. Predictors of super-response to cardiac resynchronization therapy and associated improvement in clinical outcome: the MADIT-CRT (multicenter automatic defibrillator implantation trial with cardiac resynchronization therapy) study. J Am Coll Cardiol 2012;59(25):2366-73. Doi: 10.1016/j.jacc.2012.01.065.

17. Yu C-M., Zhang Q., Yip GW-K., et al. Are left ventricular diastolic function and diastolic asynchrony important determinants of response to cardiac resynchronization therapy? Am J Cardiol 2006;98(8):1083-7. Doi: 10.1016/j.amjcard.2006.05.028.

18. Waggoner AD., Faddis MN., Gleva MJ., de las Fuentes L Dàila-Román VG. Improvements in Left Ventricular Diastolic Function After ca- đ1ac Resynchronization Therapy Are Coupled to Response in Systolic Performance. J Am Lnll Cardiol 2005;46(12):2244-9. Doi: 10.1016/j.jacc.2005.05.094.

19. Jansen AHM., van Dantzig J melle., Bracle : t t al. Improvement in diastolic function and left ventricular filling pressure induced $\mathrm{t}_{\text {, }}$ cr idiac resynchronization therapy. Am Heart $\mathbf{J}$ 2007;153(5):843-9. Doi: 10.1016/j.ahj.2n07.02.033.

20. Guazzi M. Pulmonary hypertensic $n$ in heart failure preserved ejection fraction: prevalence, pathophysiology, and clinical \& rspectives. Circ Heart Fail 2014;7(2):367-77. Doi: 10.1161/CIRCHEARTFAILL'R'

21. Almeida JG., Fontc-Larvalho R., Sampaio F., et al. Impact of the 2016 ASE/EACVI recommendations on the prevalence of diastolic dysfunction in the general population. Eur Heart J - Cardiovasc Imaging 2018;19(4):380-6. Doi: 10.1093/ehjci/jex252.

22. Damman K., van Deursen VM., Navis G., Voors AA., van Veldhuisen DJ., Hillege HL. Increased Central Venous Pressure Is Associated With Impaired Renal Function and Mortality in a Broad Spectrum of Patients With Cardiovascular Disease. J Am Coll Cardiol 2009;53(7):5828. Doi: $10.1016 /$ j.jacc.2008.08.080.

23. Stankovic I., Prinz C., Ciarka A., et al. Relationship of visually assessed apical rocking and septal flash to response and long-term survival following cardiac resynchronization therapy 
(PREDICT-CRT). Eur Heart J Cardiovasc Imaging 2016;17(3):262-9. Doi:

10.1093/ehjci/jev288.

24. Cameli M., Lisi M., Mondillo S., et al. Left atrial longitudinal strain by speckle tracking echocardiography correlates well with left ventricular filling pressures in patients with heart failure. Cardiovasc Ultrasound 2010;8:14. Doi: 10.1186/1476-7120-8-14.

25. Carluccio E., Biagioli P., Mengoni A., et al. Left Atrial Reservoir Function and Outcome in Heart Failure With Reduced Ejection Fraction. Circ Cardiovasc Imaging 2018;11(11):e007696. Doi: 10.1161/CIRCIMAGING.118.007696.

26. Dokuni K., Matsumoto K., Tatsumi K., et al. Cardiac 'es ncnronization therapy improves left atrial reservoir function through resynchronization ot $\mathrm{w}^{\mathrm{n}} \mathrm{e}$ left atrium in patients with heart failure with reduced ejection fraction. Int J Cardiovas \& L.' aging 2020;36(7):1203-12. Doi: 10.1007/s10554-020-01813-9. 
Table 1. Characteristics of the overall population and comparison according to CRT-response

\begin{tabular}{|c|c|c|c|c|}
\hline & $\begin{array}{c}\text { All } \\
(n=193)\end{array}$ & $\begin{array}{l}\text { Responders } \\
(\mathrm{n}=132,68 \%)\end{array}$ & $\begin{array}{c}\text { Non-responders } \\
(\mathrm{n}=61,32 \%)\end{array}$ & $p$-value \\
\hline \multicolumn{5}{|l|}{ Clinical data } \\
\hline Age, ys & $67 \pm 11$ & $68 \pm 10$ & $66 \pm 11$ & 0.25 \\
\hline Males & $136(70)$ & $85(64)$ & $51(83)$ & 0.004 \\
\hline Ischemic cardiomyopathy & $64(33)$ & $29(22)$ & $35(57)$ & $<0.0001$ \\
\hline NYHA & $2.31 \pm 0.61$ & $2.24 \pm 0.5^{\circ}$ & $2.48 \pm 0.65$ & 0.01 \\
\hline $\mathrm{GFR}, \mathrm{ml} / \mathrm{min}$ & $63 \pm 23$ & $65 \pm 2$ & $59 \pm 22$ & 0.10 \\
\hline QRS width, ms & $167 \pm 21$ & $16 x_{-1}$ & $166 \pm 24$ & 0.44 \\
\hline LBBB & $168(87)$ & $113(89)$ & $50(82)$ & 0.17 \\
\hline \multicolumn{5}{|l|}{ Treatment } \\
\hline Beta-blockers, n (\%) & $183,95)$ & $128(97)$ & $55(90)$ & 0.06 \\
\hline ACEI or Sartans, n (\%) & $173(9)$ & $117(89)$ & $56(92)$ & 0.34 \\
\hline Aldosterone antagonists, n (\%) & $(39)$ & $49(37)$ & $26(43)$ & 0.27 \\
\hline Diuretics, n (\%) & $165(85)$ & $90(68)$ & $75(45)$ & 0.22 \\
\hline LV dyssynchrony, n (\%) & $136(70)$ & $108(82)$ & $28(44)$ & $<0.0001$ \\
\hline Mitral regurgitation (1-4) & $1.6 \pm 0.9$ & $1.5 \pm 0.8$ & $1.8 \pm 1.1$ & 0.06 \\
\hline RWT & $0.29 \pm 0.13$ & $0.29 \pm 0.19$ & $0.29 \pm 0.19$ & 0.92 \\
\hline LV mass, $\mathrm{g} / \mathrm{m}^{2}$ & $130 \pm 39$ & $129 \pm 39$ & $134 \pm 40$ & 0.43 \\
\hline
\end{tabular}

ACE-I, angiotensin converting enzyme inhibitors; GFR, glomerular filtration rate; LBBB, left bundle branch block; LV, left ventricle; NYHA, New York heart association functional class; RWT, relative wall thickness. 
Table 2. Left ventricular systolic and diastolic function

\begin{tabular}{|c|c|c|c|c|c|c|c|}
\hline & All patients & $C R T-r$ & onders & & CRT non & ponders & \\
\hline & Baseline & Baseline & 6-months & p-value & Baseline & 6-months & p-value \\
\hline LV-EDV, ml & $210 \pm 86$ & $197 \pm 84$ & $141 \pm 64$ & $<0.0001$ & $239 \pm 85 \dagger$ & $231 \pm 89 *$ & 0.92 \\
\hline LV-ESV, ml & $153 \pm 73$ & $143 \pm 68$ & $81 \pm 50$ & $<0.0001$ & $175 \pm 76 \dagger$ & $168 \pm 78 *$ & 0.80 \\
\hline LVEF, \% & $28 \pm 8$ & $29 \pm 7$ & $45 \pm 12$ & $<0.0001$ & $28 \pm 9$ & $30 \pm 10^{*}$ & 0.44 \\
\hline GLS, \% & $-8.4 \pm 3.9$ & $-9.9 \pm 3.9$ & $-12.9 \pm 3.5$ & $<0.001$ & $-7.1 \pm 3.52 \dagger$ & $-8.1 \pm 2.9 *$ & 0.23 \\
\hline $\mathbf{L A V}_{\mathrm{i}}, \mathbf{m l} / \mathbf{m}^{2}$ & $47 \pm 17$ & $47 \pm 17$ & $36 \pm 18$ & $<0.0001$ & $51 \pm 17 \dagger$ & $45 \pm 16^{*}$ & 0.02 \\
\hline $\mathrm{E}, \mathrm{cm} / \mathrm{sec}$ & $76 \pm 33$ & $69 \pm 27$ & $66 \pm 25$ & & $87 \pm 34 \dagger$ & $79 \pm 31^{*}$ & 0.04 \\
\hline E/A & $1.3 \pm 1.0$ & $1.2 \pm 1.0$ & $1.0 \pm 0.6$ & 27 & $1.5 \pm 0.9$ & $1.5 \pm 1.05 *$ & 0.79 \\
\hline e' septal, cm/sec & $4.2 \pm 1.7$ & $4.3 \pm 1.7$ & $5.2 \pm 1.9$ & 0.01 & $4.2 \pm 1.8$ & $4.7 \pm 2.1$ & 0.16 \\
\hline e' lateral, cm/sec & $6.5 \pm 3.1$ & $6.6 \pm 3.1$ & & 0.85 & $6.2 \pm 3.2$ & $5.8 \pm 2.7$ & 0.18 \\
\hline $\mathbf{E} / \mathbf{e}^{\prime}$ & $16.0 \pm 9.3$ & $14.3 \pm 7.4$ & $12 ., \pm 6.8$ & 0.04 & $19.7 \pm 11.9 \dagger$ & $18 \pm 12 *$ & 0.47 \\
\hline $\mathrm{TRV}_{\max }, \mathrm{m} / \mathrm{sec}^{\stackrel{*}{*}}$ & $2.5 \pm 0.6$ & $2.4 \pm 0.6$ & $4 \pm 0.36$ & 0.58 & $2.7 \pm 0.6 \dagger$ & $2.6 \pm 0.4^{*}$ & 0.22 \\
\hline PAPs, mmHg & $32 \pm 13$ & $30 \pm 12$ & $29 \pm 9$ & 0.29 & $36 \pm 16 \dagger$ & $35 \pm 12 *$ & 0.35 \\
\hline
\end{tabular}

$\dagger<0.05$ vs responders at baseline, ${ }^{*} \mathrm{p}<0.05$

${ }^{*}$ At baseline, $\mathrm{TRV}_{\max }$ was detectable in $\left.\mathrm{1}^{\urcorner} 1,77 \%\right)$ responders and $51(83 \%)$ non-responders. At follow-up, $\mathrm{TRV}_{\max }$ was detectable in $98(74 \%)$ res, ?n lers and $46(75 \%)$ non-responders.

EDV, end-diastolic volume; E ; , , nd-systolic volume; GFR, glomerular filtration rate; GLS, global longitudinal strain; LV, left $、$ ntıcle; $\mathrm{LAV}_{\mathrm{i}}$, indexed left atrial volume; LVEF, left ventricular ejection fraction; PAPs, estimated $\mathrm{pu}^{1 \mathrm{~m}}$, nary systolic pressure; $\mathrm{TRV}_{\max }$, maximal tricuspid regurgitation velocity. 
Table 3. Clinical and echocardiographic parameters according to diastolic dysfunction.

Patients with indeterminate diastolic dysfunction were not included in the analysis.

\begin{tabular}{|c|c|c|c|}
\hline & $\begin{array}{l}\text { Grade I DD } \\
(n=105,55 \%)\end{array}$ & $\begin{array}{l}\text { Grade II-III DD } \\
\quad(\mathrm{n}=72,37 \%)\end{array}$ & p-value \\
\hline \multicolumn{4}{|l|}{ Clinical data } \\
\hline Age, ys & $65 \pm 11$ & $69 \pm 10$ & 0.007 \\
\hline Males, n (\%) & $73(70)$ & $53(74)$ & 0.34 \\
\hline Ischemic cardiomyopathy, n (\%) & $26(25)$ & $32(44)$ & 0.007 \\
\hline NYHA & $2.2 \pm 0.6$ & $.5 \pm 0.6$ & $<0.0001$ \\
\hline QRS width, ms & $165 \pm 18$ & $171 \pm 24$ & 0.13 \\
\hline $\mathrm{GFR}, \mathrm{ml} / \mathrm{min}$ & $68 \pm 22$ & $54 \pm 22$ & $<0.0001$ \\
\hline $\mathrm{LBBB}, \mathrm{n}(\%)$ & $94(90)$ & $60(83)$ & 0.28 \\
\hline Beta-blockers, n(\%) & $c+9 u$ & $63(80)$ & 0.42 \\
\hline ACEI or Sartans, n (\%) & $101,96)$ & $68(94)$ & 0.42 \\
\hline Aldosterone-antagonists n (\%) & $33(32)$ & $33(47)$ & 0.03 \\
\hline Diuretics, n (\%) & $66(83)$ & $60(63)$ & 0.002 \\
\hline \multicolumn{4}{|l|}{ Echocardiographic data } \\
\hline LV mass, $\mathrm{g} / \mathrm{m}^{2}$ & $125 \pm 36$ & $135 \pm 42$ & 0.07 \\
\hline RWT & $0.30 \pm 0.16$ & $0.28 \pm 0.07$ & 0.23 \\
\hline LV-EDV, ml & $201 \pm 82$ & $219 \pm 90$ & 0.18 \\
\hline LV-ESV, ml & $145 \pm 69$ & $112 \pm 39$ & 0.25 \\
\hline LVEF, \% & $29 \pm 7$ & $27 \pm 9$ & 0.22 \\
\hline LV-EDV ${ }_{\mathrm{FU}}, \mathrm{ml}$ & $150 \pm 66$ & $190 \pm 92$ & $<0.0001$ \\
\hline LV-ESV ${ }_{\mathrm{FU}}, \mathrm{ml}$ & $87 \pm 55$ & $132 \pm 81$ & $<0.0001$ \\
\hline $\mathrm{LVEF}_{\mathrm{FU}}, \%$ & $45 \pm 13$ & $36 \pm 13$ & $<0.0001$ \\
\hline LV dyssynchrony, n\% & $81(77)$ & $43(60)$ & 0.01 \\
\hline
\end{tabular}


E wave, $\mathrm{cm} / \mathrm{sec}$
$58 \pm 20$

$0.75 \pm 0.31$

$40 \pm 13$

$12 \pm 6$

$2.2 \pm 0.5$

$26 \pm 9$

$86(82)$
$98 \pm 34$

$<0.0001$

$2.2 \pm 1.5$

$<0.0001$

LAVi, $\mathrm{ml} / \mathrm{m}^{2}$

E/e'

$\mathrm{TRV}_{\max }, \mathrm{m} / \mathrm{sec}$

PAPs, mmHg

Responders
$55 \pm 18$

$<0.0001$

$22 \pm 10$

$<0.0001$

$2.9 \pm 0.5$

$<0.0001$

$41 \pm 14$

$<0.0001$

$36(50)$

$<0.0001$ 
Table 4. Univariable regression analysis showing clinical and echocardiographic predictors of prognosis (Panel A). The association between diastolic dysfunction grades and outcome at univariable analysis is depicted in Panel B. In this panel, the associations are assessed with different grades of diastolic dysfunction as reference.

\begin{tabular}{|c|c|}
\hline PANEL A & HR (95\% CI) \\
\hline Age & $1.03(0.98-1.07)$ \\
\hline NYHA & $4.33(2.08-9.05)$ \\
\hline Ischemic etiology & $3.5 ;(0.64-3.52)$ \\
\hline LBBB & $(' 44,0.19-1.05)$ \\
\hline QRS duration & $12(1.00-1.04)$ \\
\hline LVEF & $0.97(0.92-1.01)$ \\
\hline Mitral regurgitation & $1.49(1.01-2.24)$ \\
\hline LV dyssynchrony & $0.31(0.15-0.65)$ \\
\hline Responders & $0.27(0.13-0.57)$ \\
\hline $\mathrm{E} / \mathrm{e}^{\prime}>14$ & $2-64(1.18-5.88)$ \\
\hline $\mathrm{LAV}_{\mathrm{i}}>34 \mathrm{ml} / \mathrm{m}^{2}$ & $4.04(1.51-10.83)$ \\
\hline $\mathrm{TRV}_{\max }>2.8 \mathrm{~m} / \mathrm{sec}$ & $3.08(1.35-7.00)$ \\
\hline \multicolumn{2}{|l|}{ PANEL B } \\
\hline Grade I DD & Ref \\
\hline Grade II DD (ref grade I) & $6.04(2.32-15.77)$ \\
\hline Grade III DD (ref grade I) & 4.64 (1.49-14.39) \\
\hline Grade II DD & Ref \\
\hline Grade I (ref Grade II) & $0.17(0.06-0.43)$ \\
\hline Grade III (ref Grade II) & $0.77(0.29-2.00) 0.59$ \\
\hline Grade III DD & Ref \\
\hline Grade I (ref Grade III) & $0.21(0.07-0.66)$ \\
\hline Grade II (ref Grade III) & $1.30(0.50-3.39)$ \\
\hline
\end{tabular}


Figure 1. Algorithm for the assessment of diastolic dysfunction

2C, 2-chamber view; 4C, 4-chamber virew; DD, diastolic dysfunction, LA, left atrium, LAVi, indexed left atrial volume; $\mathrm{TRV}_{\max }$, maximal tricuspid regurgitation velocity

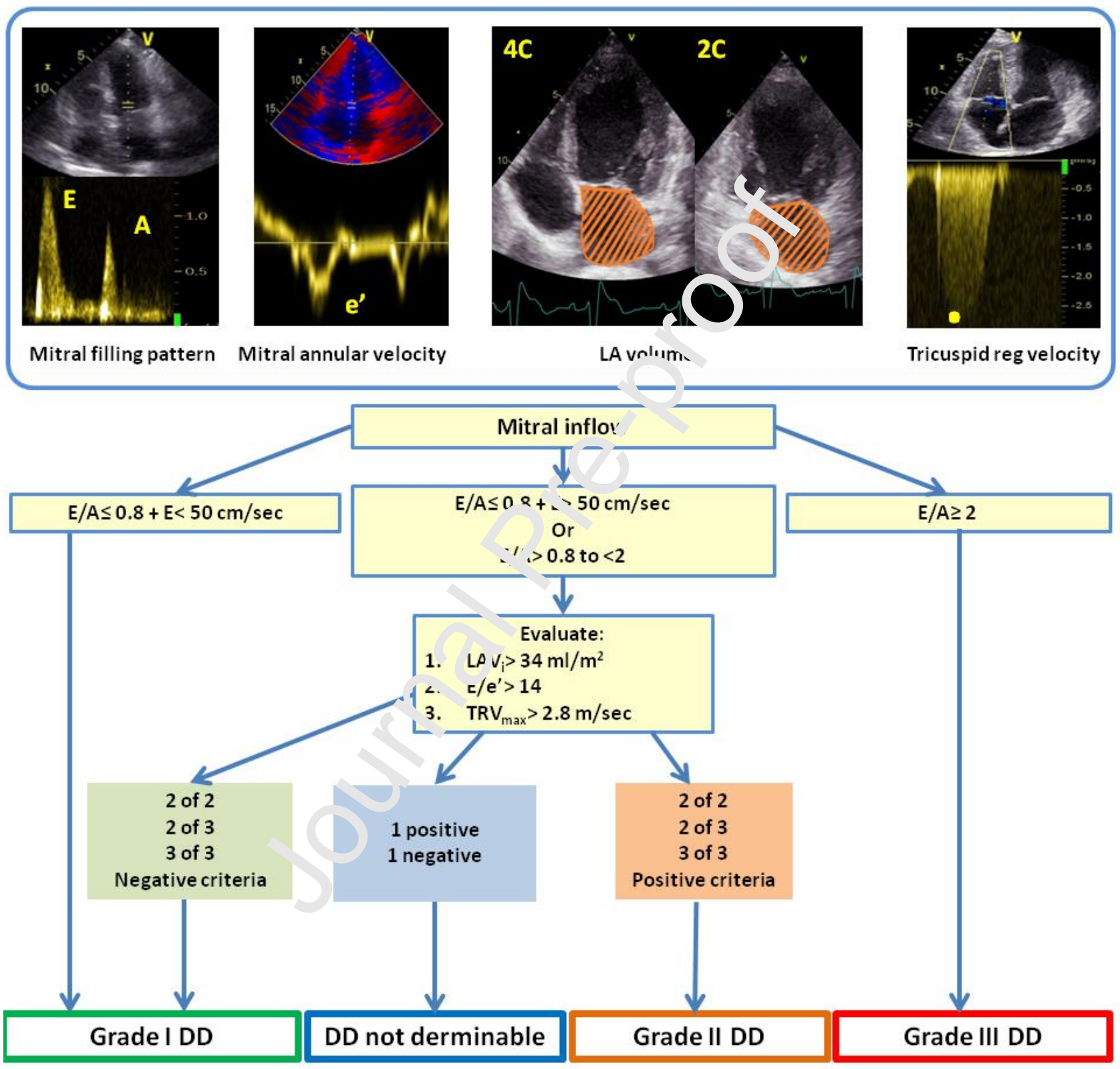


Figure 2 A. Prevalence of diastolic dysfunction at baseline (A) and 6-month follow-up (B) in the overall population

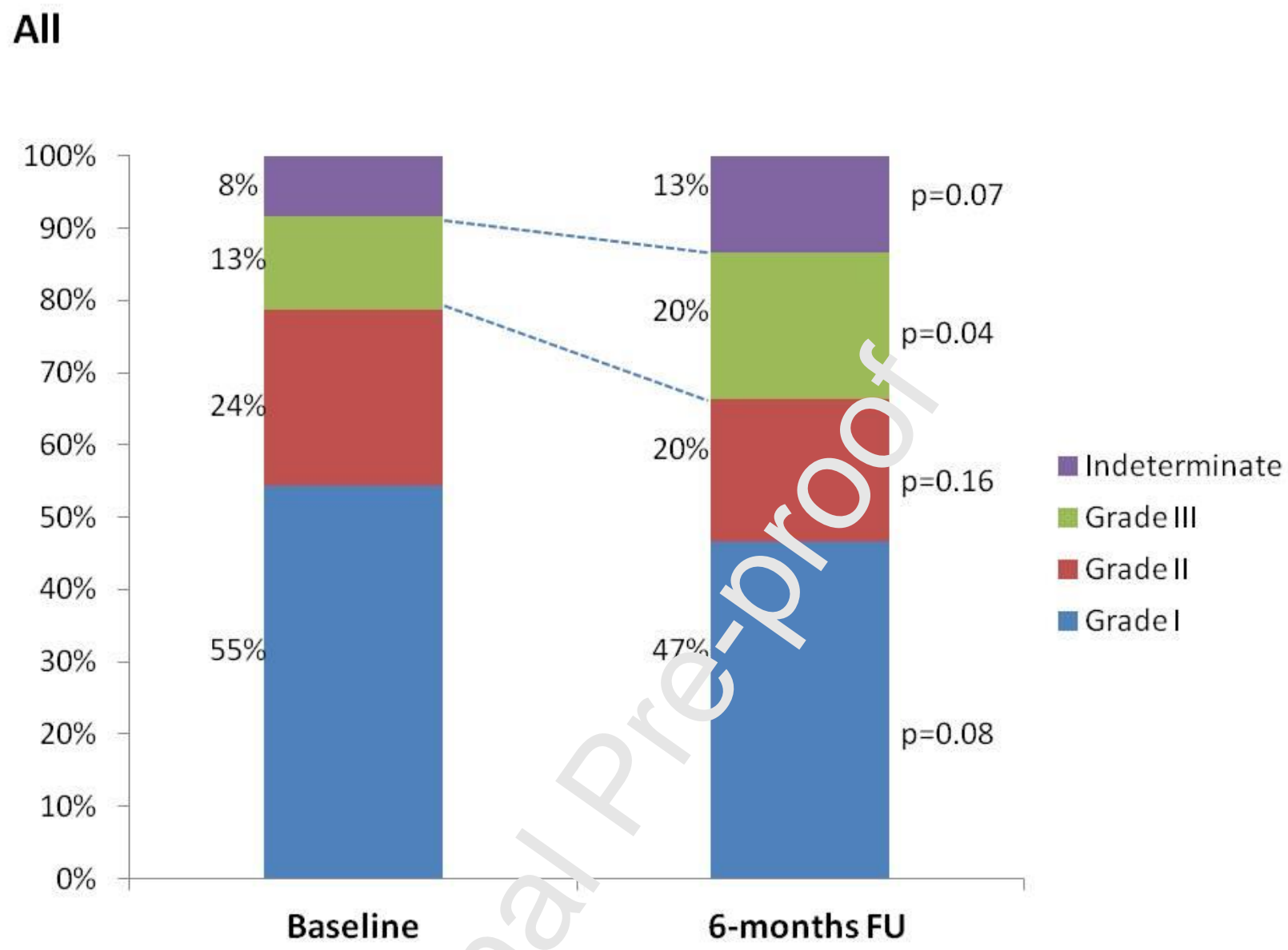


Figure 2B Prevalence of diastolic dysfunction at baseline in responders and non-responders

\section{Baseline}

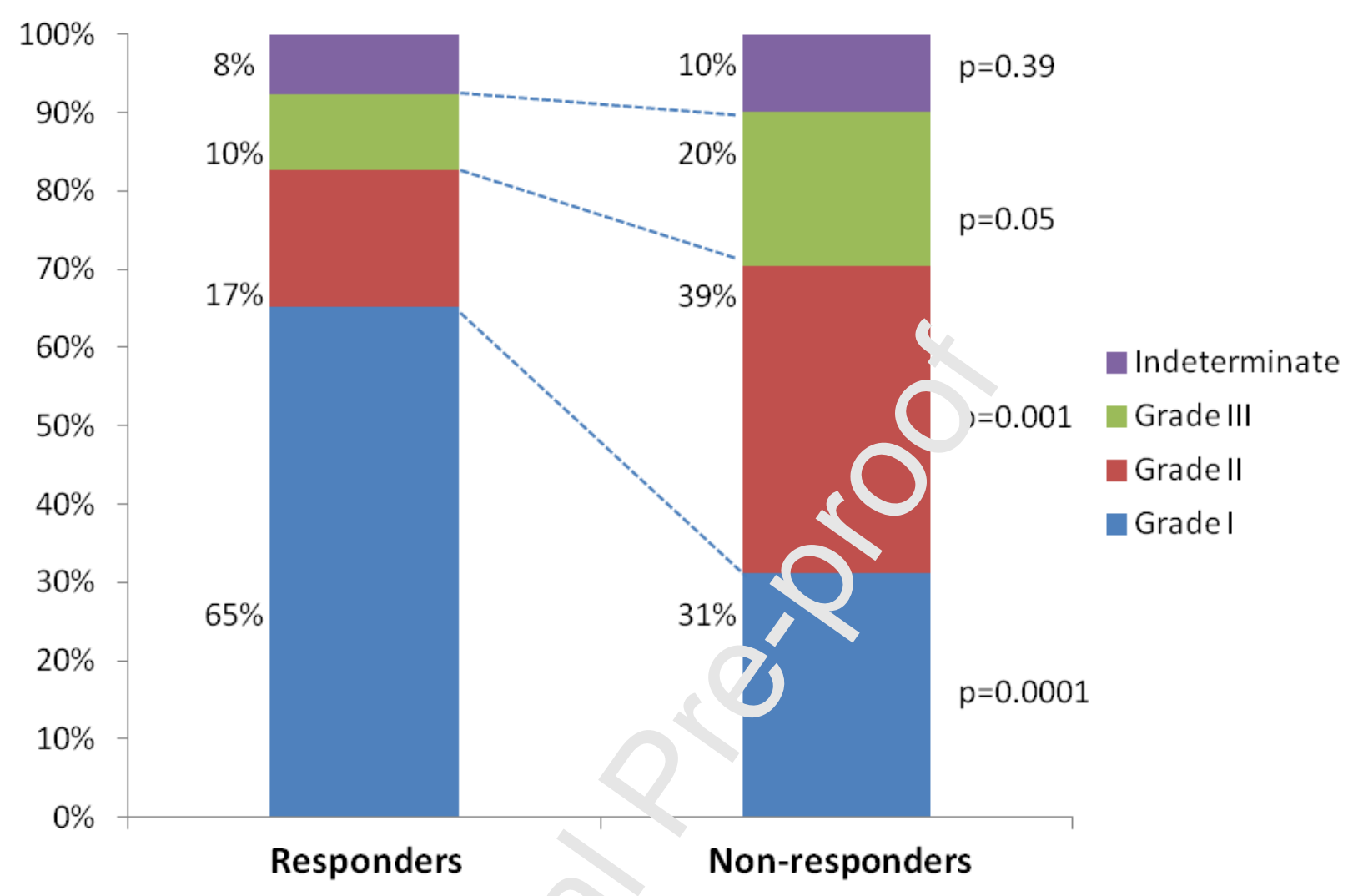


Figure 2C Prevalence of diastolic dysfunction at baseline and 6-month FU in non-responders

\section{Non-responders}

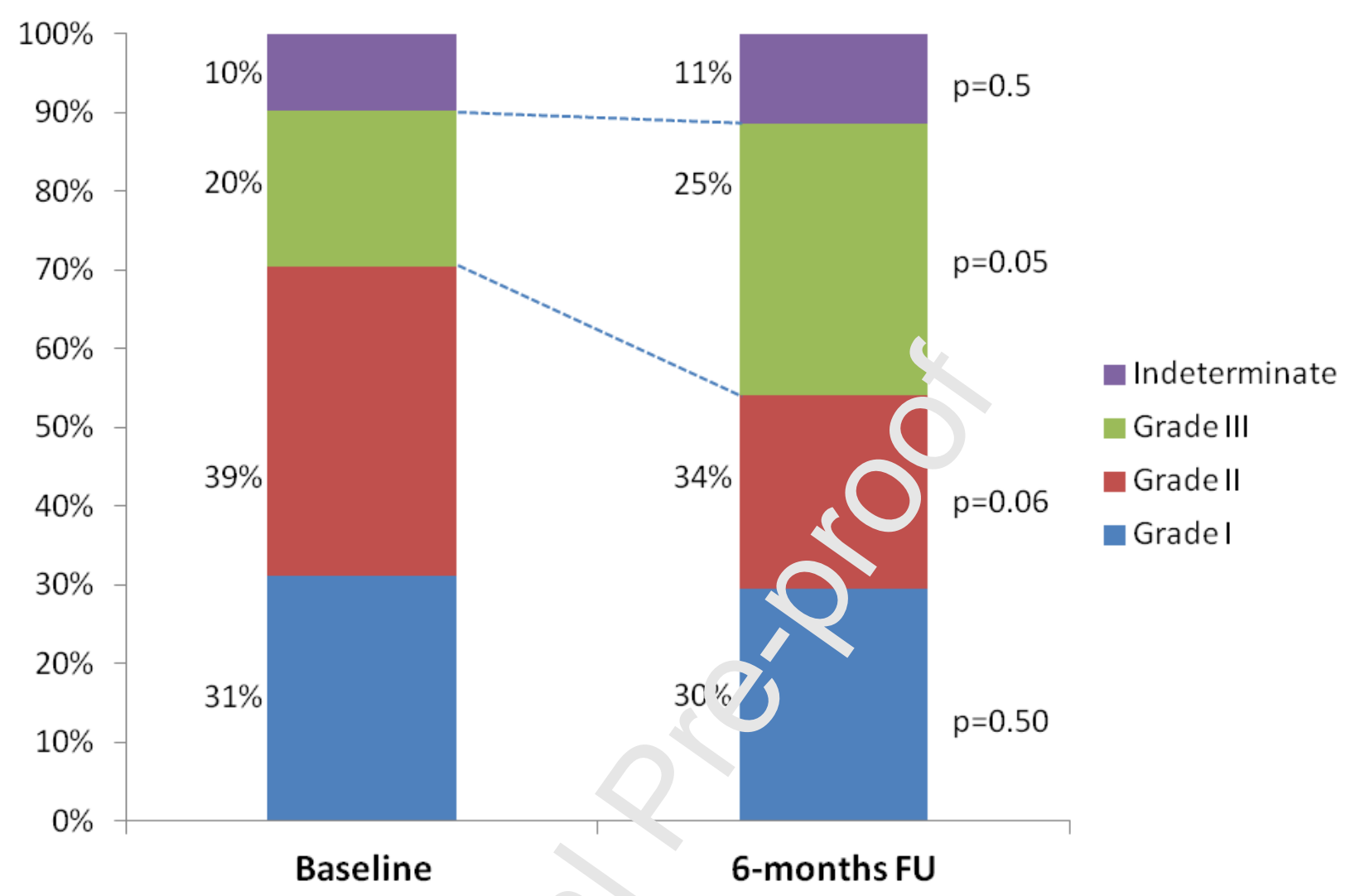


Figure 2D Prevalence of diastolic dysfunction at baseline and 6-month FU in responders

\section{Responders}

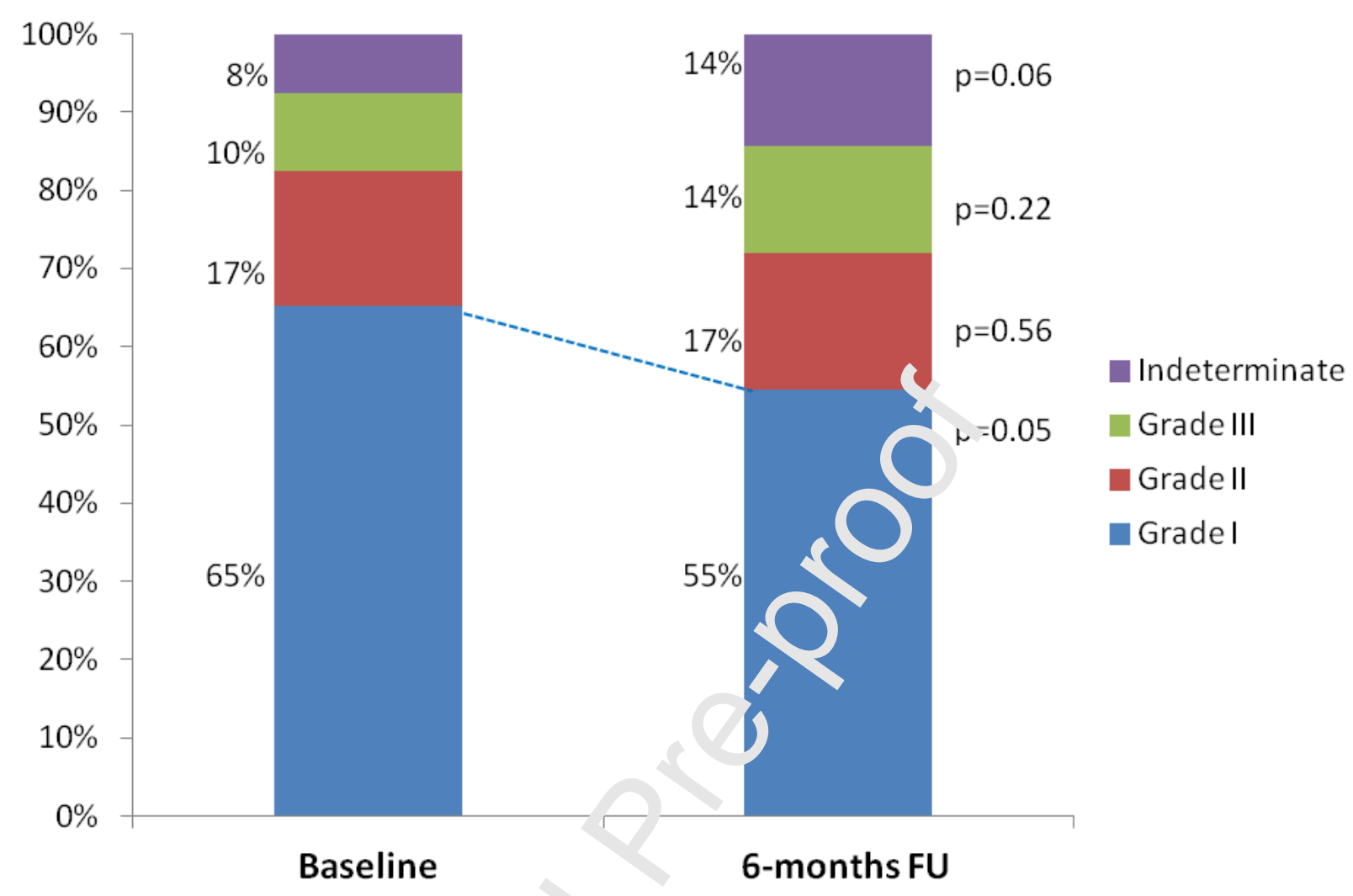


Figure 3. Forest plot depicting the main predictors of prognosis at multivariable regression analysis.

DD, diastolic dysfunction; NYHA, New York Heart Association functional class

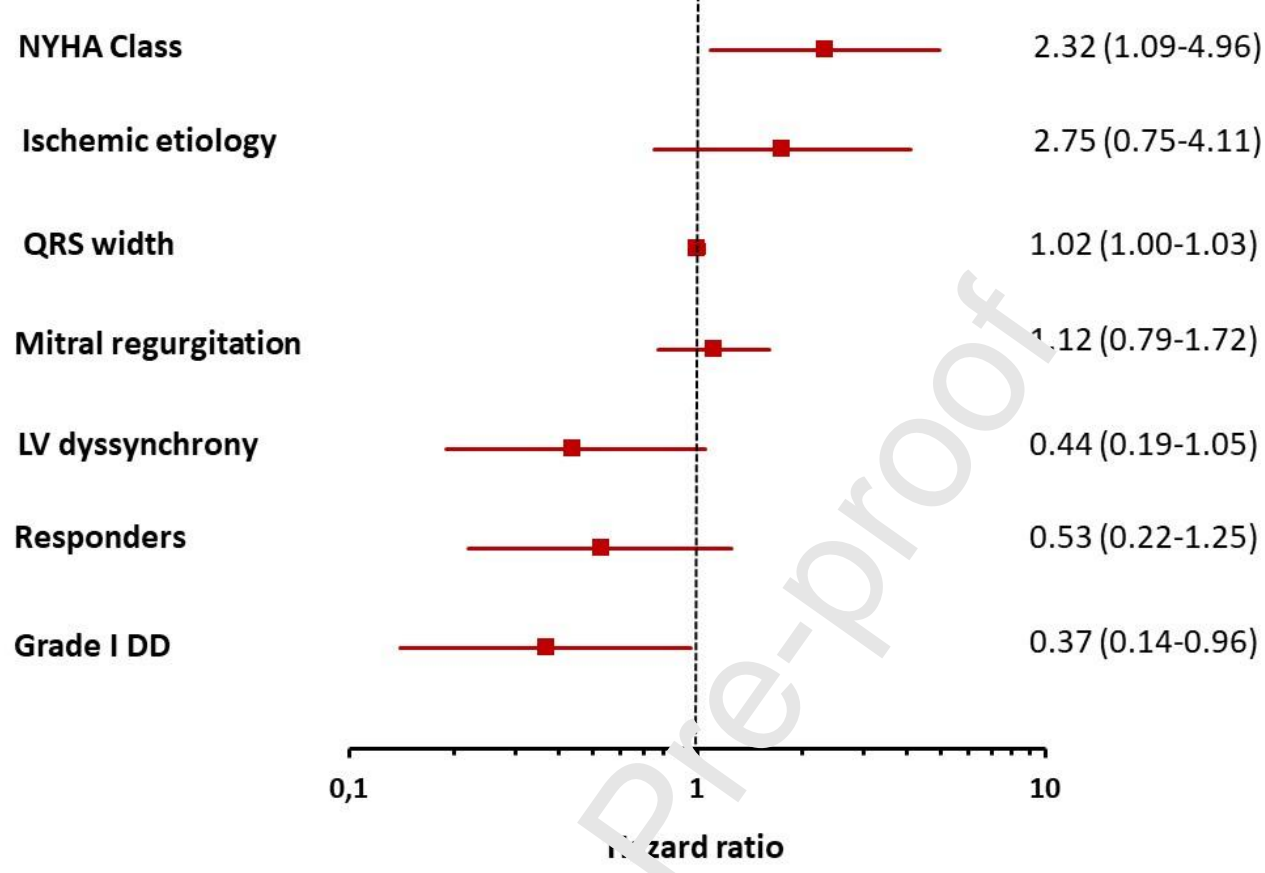


Figure 4A. Kaplain-Meier curve depicting survival according to diastolic dysfunction

DD, diastolic dysfunction

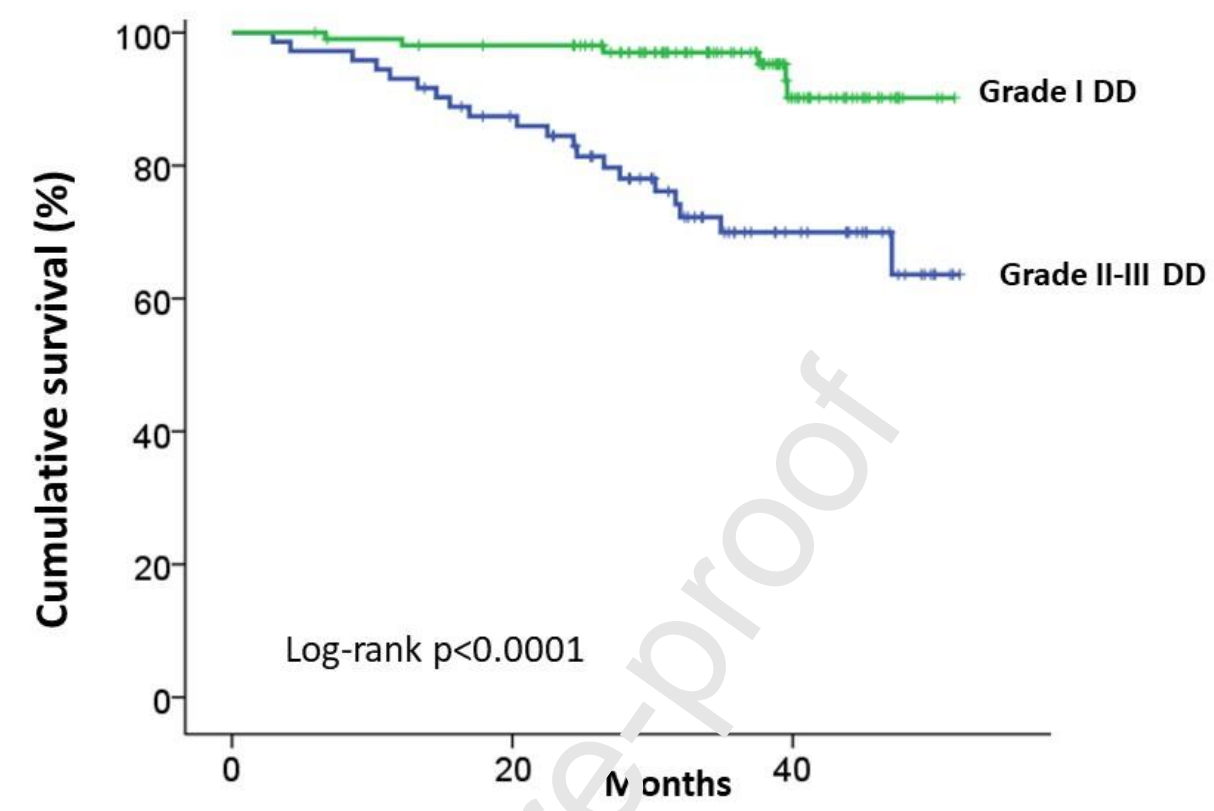

Number at risk

Grade I

Grade II-III
105

72
85

$-2$
65

32 
Figure 4B Kaplain-Meier curve depicting survival according to diastolic dysfunction and

\section{CRT-response}

DD, diastolic dysfunction; $\mathrm{R}+$, CRT positive response; R-, CRT negative response

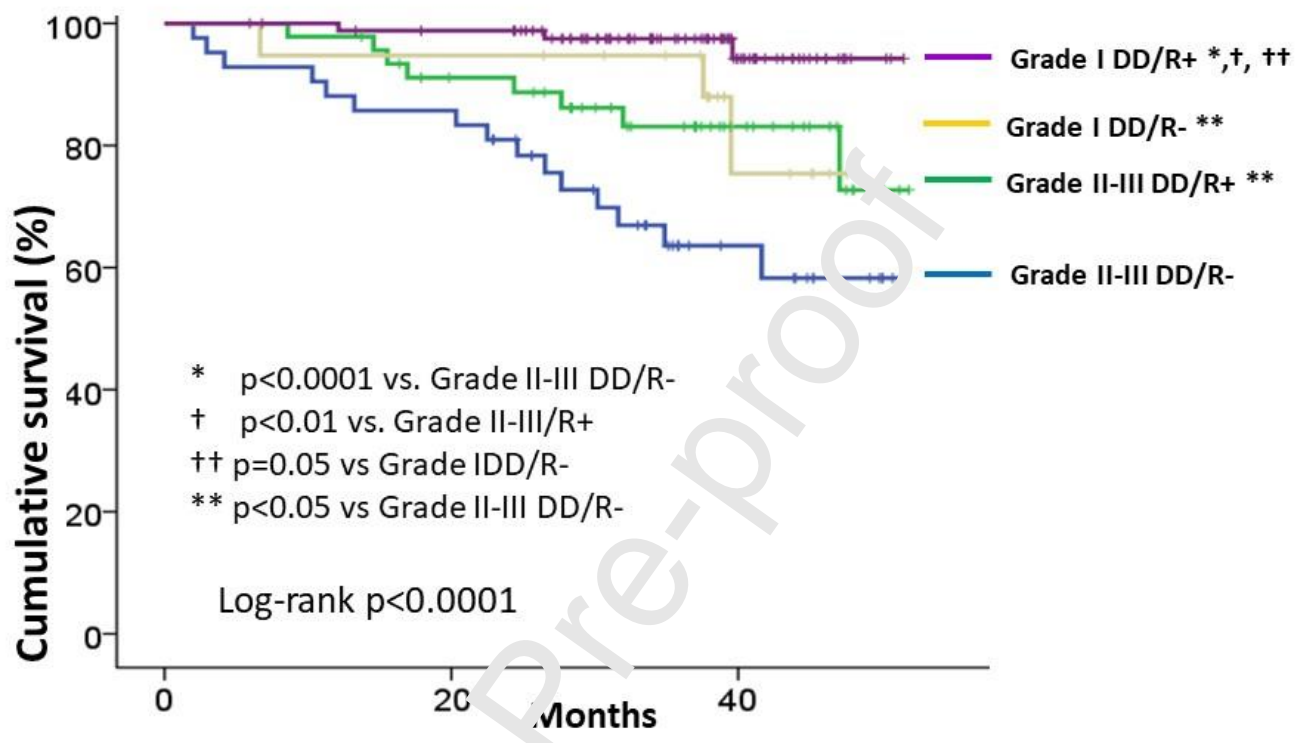

Number at risk

Grade I DD/R+

Grade I DD/R-

46

38

16

Grade II-III DD/R+

19

18

6

Grade II-III DD/R-

42

35

12 
Figure 4C Kaplain-Meier curve depicting survival according to diastolic dysfunction and left ventricular dyssynchrony

DD, diastolic dysfunction; No Dyss, absence of left ventricular dyssynchrony; Dyss, presence of left ventricular dyssynchrony

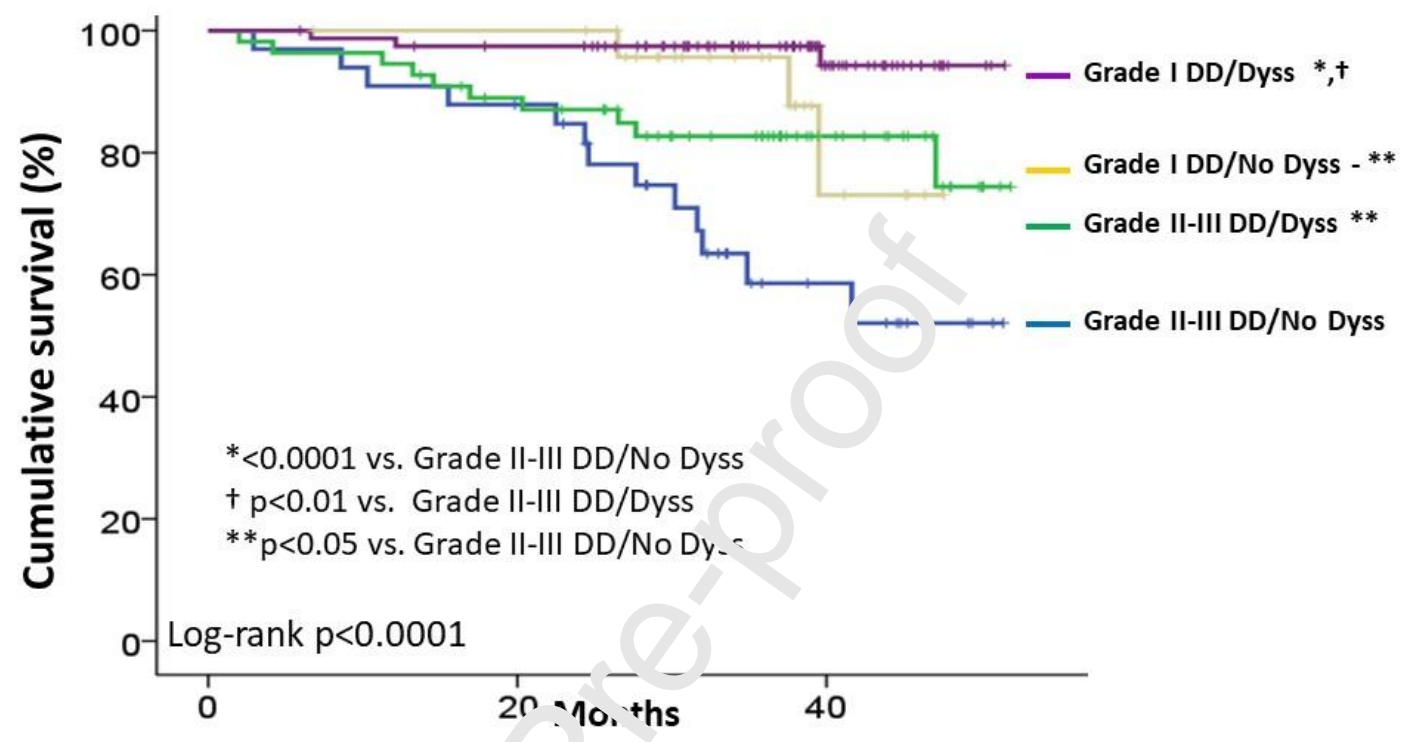

Number at risk

Grade I DD/Dyss

Grade I DD/No Dyss 


\section{Supplementary Figure 1 A-F.}

Inter observer variability for left end-systolic volume between the 3 enrolling centres is displayed as linear regression with inter-class correlation coefficients and Bland-Altman plots.

ICC, interclass correlation coefficient; CI, confidence interval; LVESV, left ventricular end-systolic volume, $\mathrm{O}=$ Oslo, $\mathrm{R}=$ Rennes, $\mathrm{L}=$ Leuven.

A

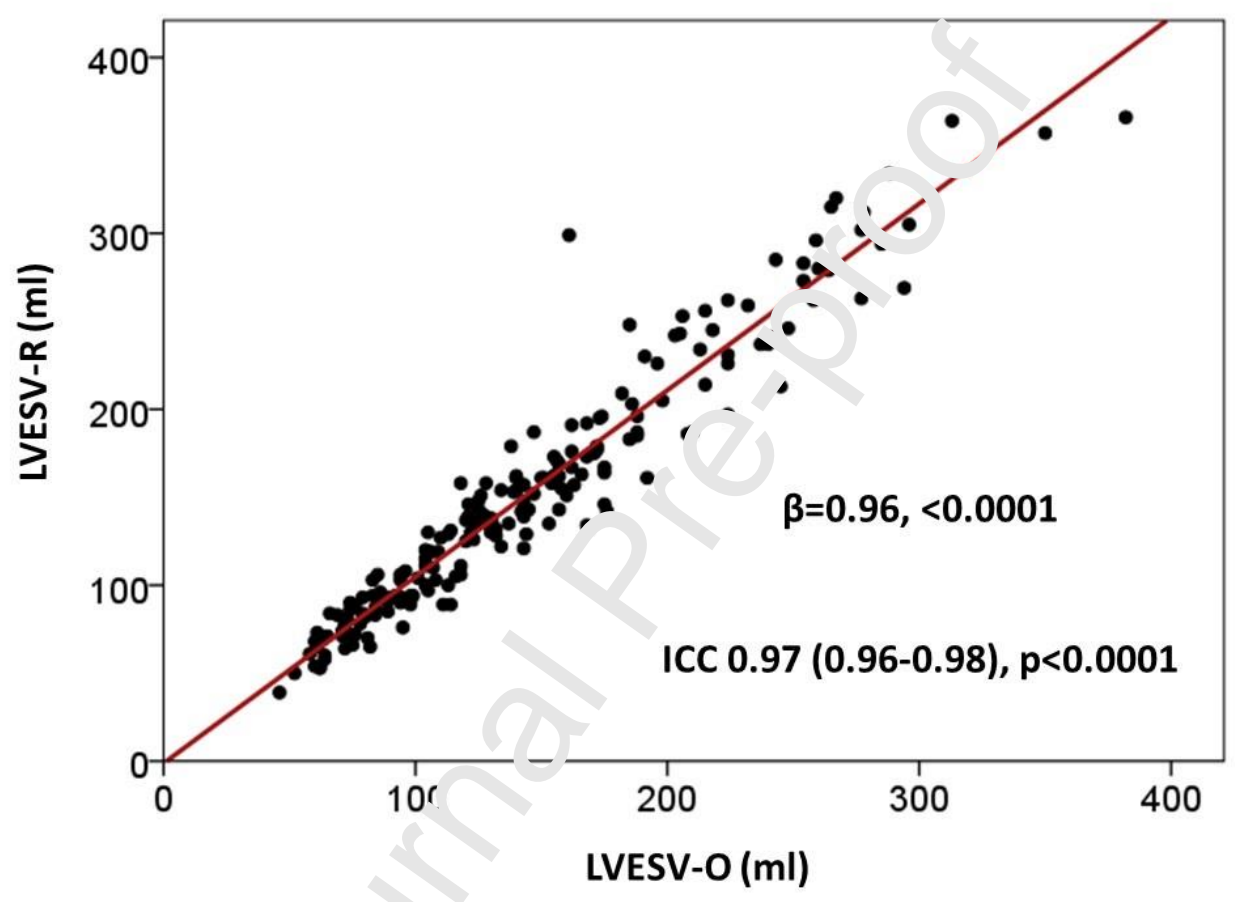


B

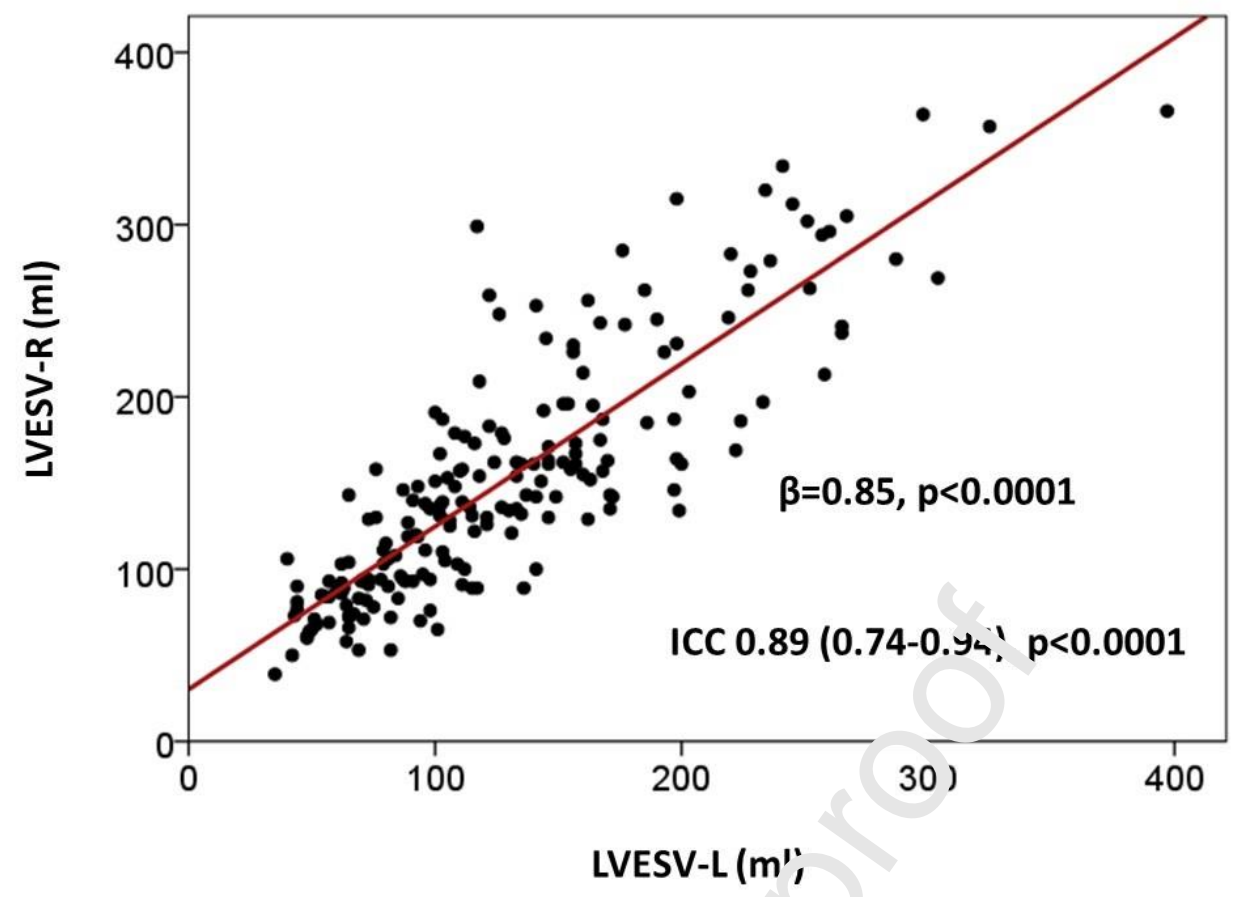


C

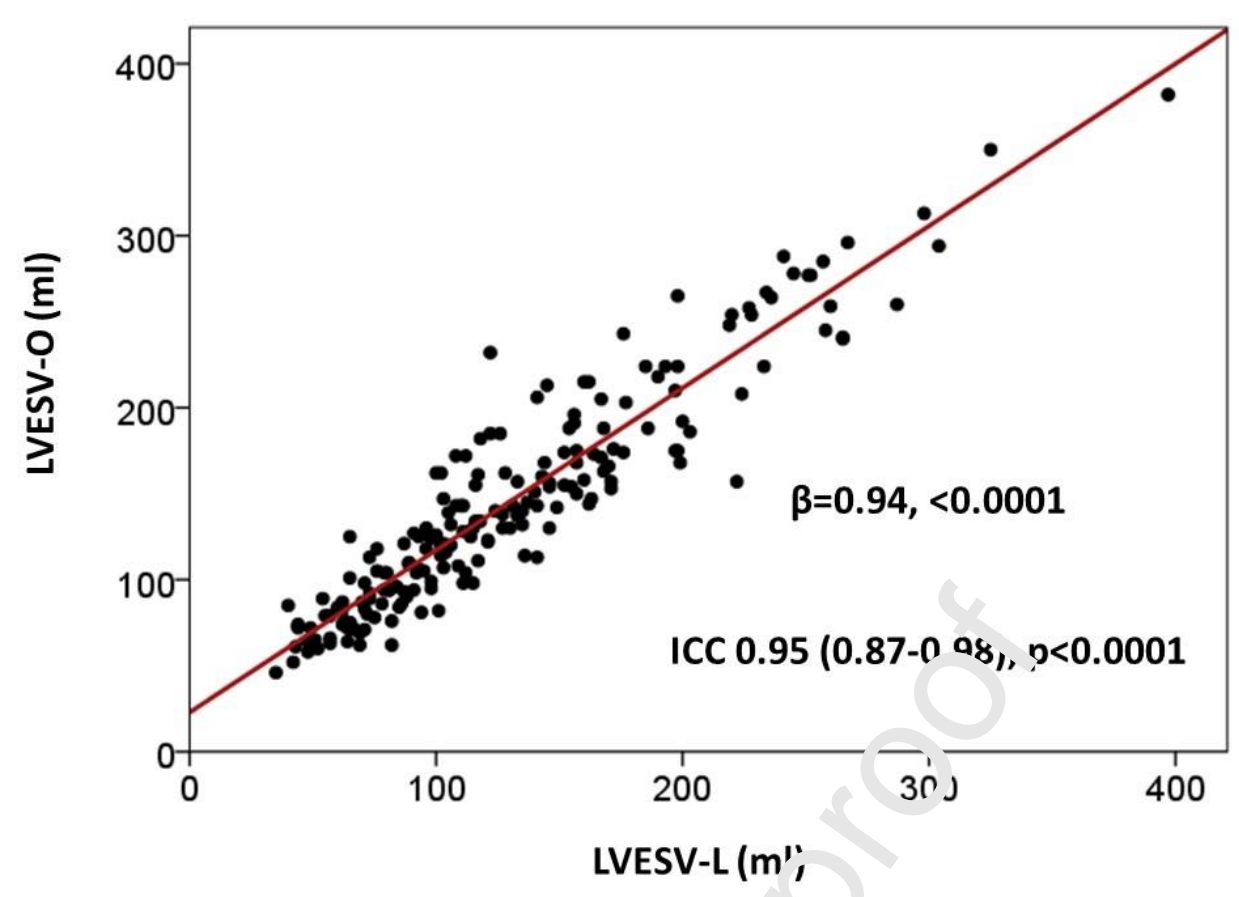


D

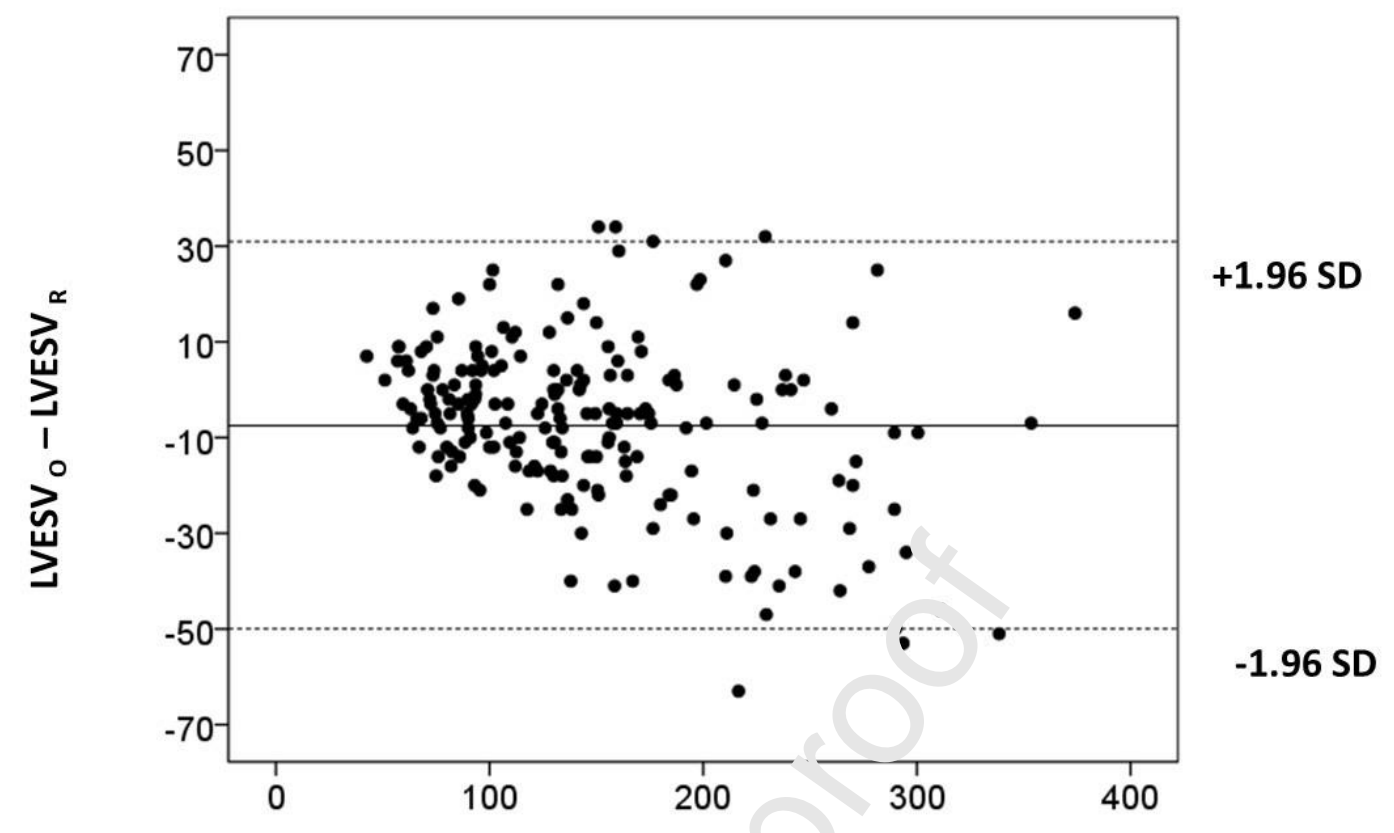

Mean IV $\dot{c} \mathrm{SV}_{\mathrm{O}-\mathrm{R}}$ 
E

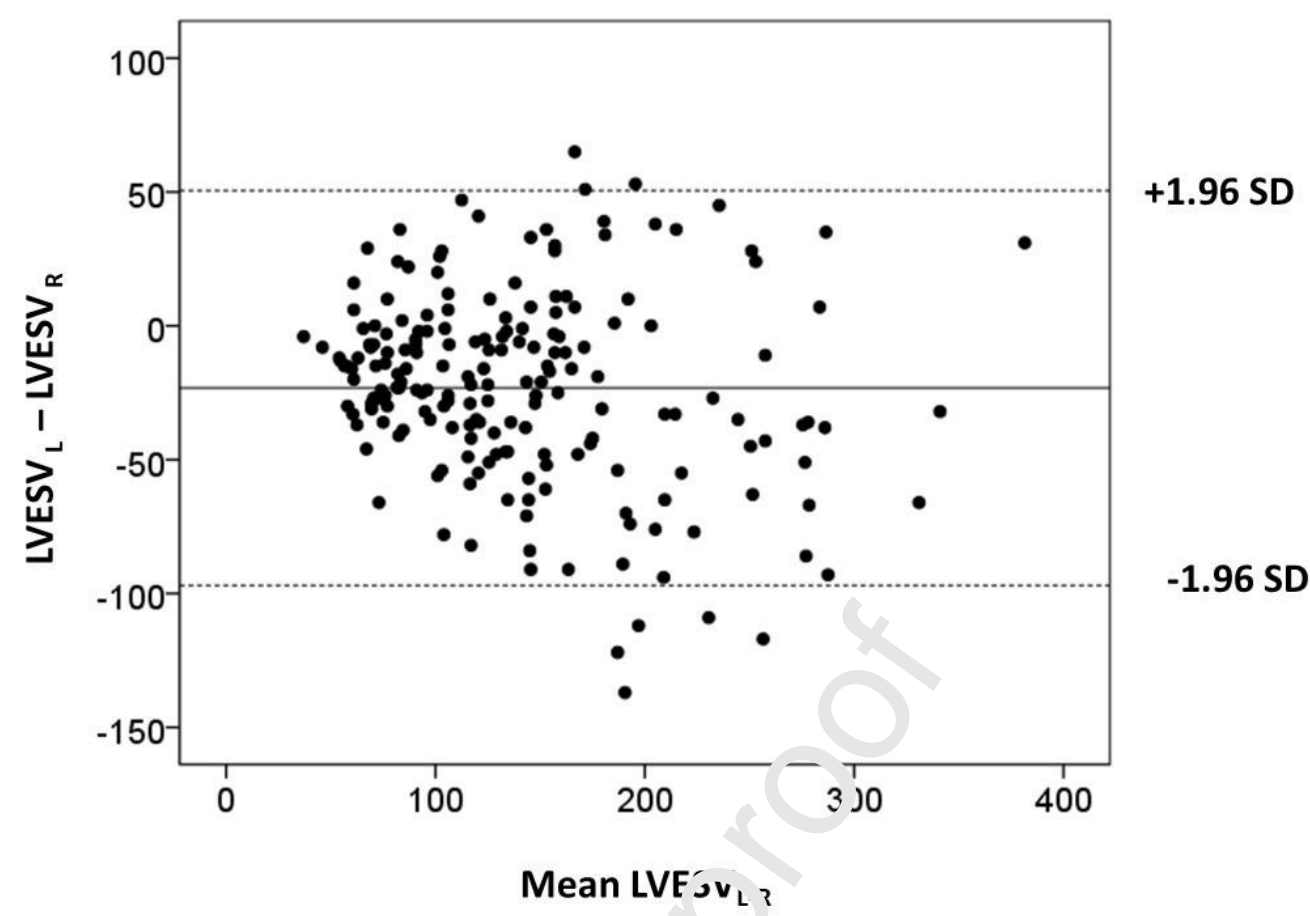


$\mathbf{F}$

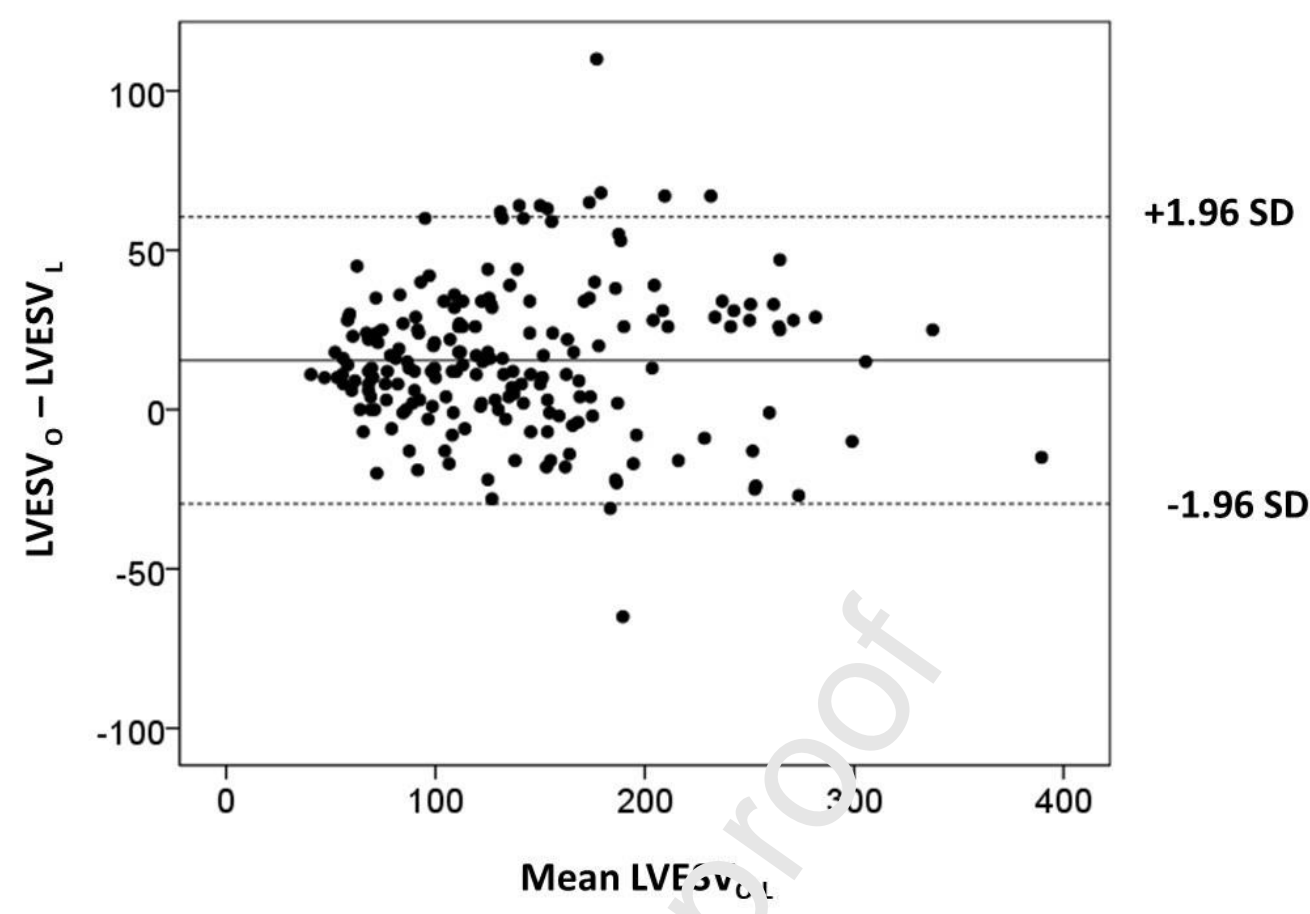


Supplementary Figure 2 Forest plot depicting the main predictors of prognosis at ultivariable regression analysis in an alternative model including left bundle branch block DD, diastolic dysfunction; LBBB, left bundle branch block; NYHA, New York Heart Association functional class.

NYHA Class
Ischemic etiology
QRS width
LBBB
Mitral regurgitation
LV dyssyncrony
Responders
Grade I DD

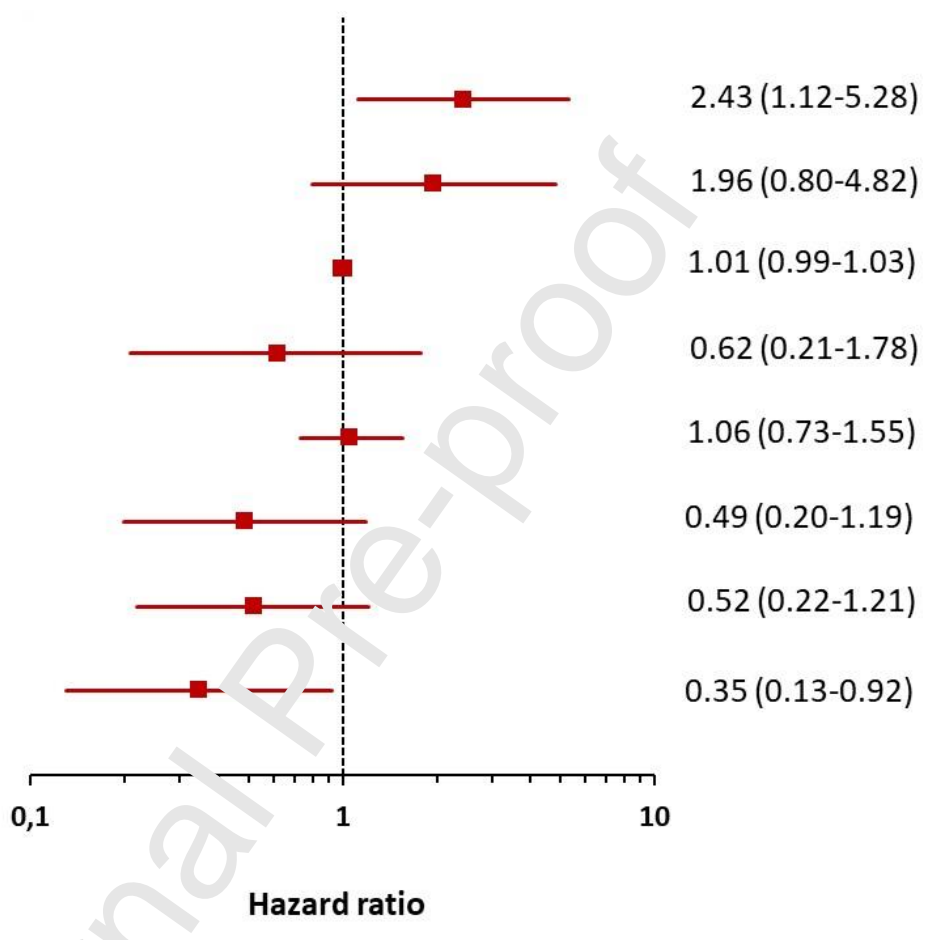


Supplementary Figure 3. Forest plot depicting the main predictors of prognosis at multivariable regression analysis in an alternative model including $E$ /e', indexed left atrial volume and maximal tricuspid regurgitation velocity for the assessment instead of the diastolic dysfunction grading proposed by Nagueh et al.

$\mathrm{LAV}_{\mathrm{i}}$, indexed left atrial volume; NYHA, New York Heart Association functional class; TRV $\mathrm{max}_{\max }$, maximal tricuspid regurgitation velocity

NYHA Class
Ischemic etiology
QRS width
Mitral regurgitation
LV dyssynchrony
Responders
E/e' $^{\prime}>14$
LAV $_{\mathrm{i}}>34 \mathrm{ml} / \mathrm{m}^{2}$
TRV $_{\max }>2.8 \mathrm{~m} / \mathrm{sec}$

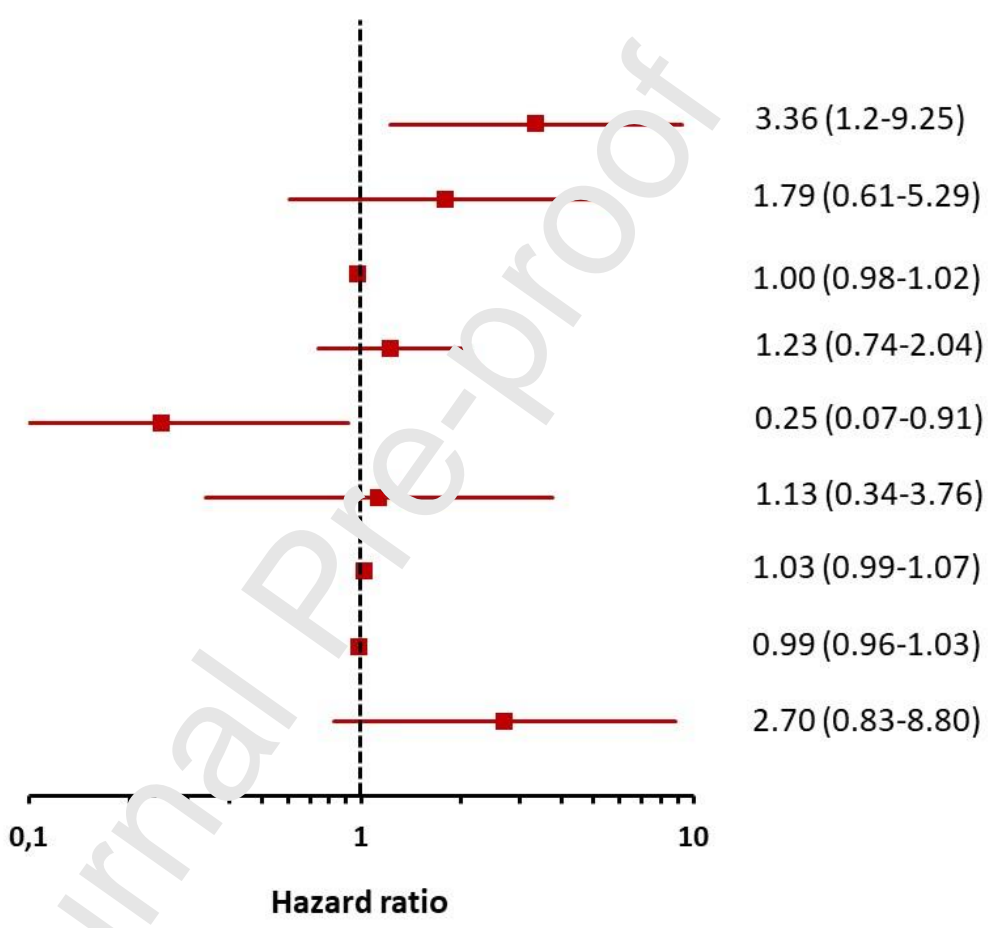

Highlights

- Conflicting data ex: about the relationship between cardiac resynchronization therapy (CRT) and diastolic function.

- One-hundred ninety-three patients (age: $67 \pm 11$ years, QRS width: $167 \pm 21 \mathrm{~ms}$ ) were included in this multicentre prospective study about the value of imaging for CRT. CRT was associated with a degradation of diastolic dysfunction in non-responders. Grade I diastolic dysfunction was associated with a better outcome (HR 0.36, 95\% CI: 0.14-0.85).

- Non-responders with grade II or grade III diastiloc dysfunction had the worse prognosis (HR 4.36, 95\%CI: 2.10-9.06). 
- So, the evaluation of diastolic dysfunction in CRT candidates is crucial for best stratification of patients according to their own risk of cardio-vascular event, independently from CRTresponse. 